\title{
Experience-dependent changes in excitatory and inhibitory receptor subunit expression in visual cortex
}

\author{
Brett R. Beston ${ }^{1,2}$, David G. Jones ${ }^{1}$ and Kathryn M. Murphy ${ }^{1,2 *}$ \\ McMaster Integrative Neuroscience Discovery and Study Program, McMaster University, Hamilton, ON, Canada \\ 2Department of Psychology, Neuroscience and Behaviour, McMaster University, Hamilton, ON, Canada
}

Edited by:

Susana Cohen-Cory, University of California, USA

Reviewed by:

Lutgarde Arckens, Catholic University, Belgium

Leonard White, Duke University, USA

*Correspondence:

Kathryn M. Murphy, McMaster Integrative Neuroscience Discovery and Study Program, McMaster University, 1280 Main Street West, Hamilton, ON, Canada L8S 4K1. e-mail:kmurphy@mcmaster.ca
Experience-dependent development of visual cortex depends on the balance between excitatory and inhibitory activity. This activity is regulated by key excitatory (NMDA, AMPA) and inhibitory $\left(G A B A_{A}\right)$ receptors. The composition of these receptors changes developmentally, affecting the excitatory-inhibitory (E/I) balance and synaptic plasticity. Until now, it has been unclear how abnormal visual experience affects this balance. To examine this question, we measured developmental changes in excitatory and inhibitory receptor subunits in visual cortex following normal visual experience and monocular deprivation. We usedWestern blot analysis to quantify expression of excitatory (NR1, NR2A, NR2B, GluR2) and inhibitory (GABA $\left.\alpha 1, G_{A} A_{A} \alpha 3\right)$ receptor subunits. Monocular deprivation promoted a complex pattern of changes in receptor subunit expression that varied with age and was most severe in the region of visual cortex representing the central visual field. To characterize the multidimensional pattern of experience-dependent change in these synaptic mechanisms, we applied a neuroinformatics approach using principal component analysis. We found that monocular deprivation (i) causes a large portion of the normal developmental trajectory to be bypassed, (ii) shifts the E/I balance in favor of more inhibition, and (iii) accelerates the maturation of receptor subunits. Taken together, these results show that monocularly deprived animals have an abnormal balance of the synaptic machinery needed for functional maturation of cortical circuits and for developmental plasticity. This raises the possibility that interventions intended to treat amblyopia may need to address multiple synaptic mechanisms to produce optimal recovery.

Keywords: plasticity, development, monocular deprivation, excitatory-inhibitory balance, amblyopia, NMDA, AMPA, GABA $_{A}$

\section{INTRODUCTION}

Disrupting visual input to one eye during the critical period of visual development leads to a dramatic reduction in the acuity of the deprived eye, a condition commonly known as lazy-eye (amblyopia). In kittens, the peak of this plasticity is at $4-6$ weeks of age (Olson and Freeman, 1980) and reflects an experience-dependent competitive loss of inputs (Wiesel and Hubel, 1965; Hubel and Wiesel, 1970; Antonini and Stryker, 1993) and a depression of synaptic responses to the deprived eye in visual cortex (Rittenhouse et al., 1999). These changes depend on the activation of $N$-methylD-aspartate (NMDA), alpha-amino-3-hydroxy-5-methyl-4-isoxazole (AMPA), and gamma-aminobutyric-acid $\left(\mathrm{GABA}_{\mathrm{A}}\right)$ receptors as well as the roles that these receptors play in mediating long-term potentiation (LTP), long-term depression (LTD), synaptic scaling, and setting the excitatory-inhibitory (E/I) balance in visual cortex (Kirkwood and Bear, 1994; Hensch et al., 1998; Heynen et al., 2003; Fagiolini et al., 2004; Turrigiano and Nelson, 2004).

The excitatory-inhibitory balance has become an important focus for studies exploring the role of experience-dependent plasticity (Hensch, 2005) and synaptic scaling (Turrigiano and Nelson, 2004; Maffei and Turrigiano, 2008b) in development of visual cortical function. Initiation of the critical period for ocular dominance plasticity and maturation of receptive field properties in visual cortical neurons depend on the $\mathrm{E} / \mathrm{I}$ balance in visual cortex (Fagiolini et al., 2004; Hensch, 2005; Marino et al., 2005). Mice lacking the GABA-synthesizing enzyme glutamic acid decarboxylase (GAD65) have reduced inhibitory transmission and are insensitive to monocular deprivation induced shifts in ocular dominance (Hensch et al., 1998). This plasticity, however, can be rescued at any age in GAD65 knockout mice by tipping the $\mathrm{E} / \mathrm{I}$ balance toward inhibition with infusion of diazepam into the visual cortex (Fagiolini and Hensch, 2000; Iwai et al., 2003; Fagiolini et al., 2004). In addition, the start of the critical period in GAD65 knockout mice can be initiated prematurely by enhancing inhibition in the visual cortex with benzodiazepines (Fagiolini and Hensch, 2000; Iwai et al., 2003). The experience-dependent changes that occur just before, versus during the critical period, reflect different mechanisms (Smith and Trachtenberg, 2007), especially in layer 4 where pre-critical period deprivation increases excitability, while deprivation during the critical period strengthens inhibition which reduces excitability in layer 4 (Maffei et al., 2006, 2010; Maffei and Turrigiano, 2008a). Excitatory mechanisms also affect the E/I balance. This includes changes in GAD65 knockout mice where ocular dominance plasticity is regulated by expression of the NR2A subunit of the NMDA receptor (Kanold et al., 2009). Finally, direct manipulation of excitation by selective deletion of the NR2A subunit prolongs NMDA currents, shifting the balance toward excitation and effectively weakens experience-dependent plasticity in visual cortex (Fagiolini et al., 2003). 
The delicate balance between excitatory and inhibitory neurotransmission and many aspects of experience-dependent plasticity in the visual cortex are mediated by activation of excitatory (NMDA and AMPA) and inhibitory $\left(\mathrm{GABA}_{\mathrm{A}}\right)$ receptors. AMPA and NMDA are the two major types of glutamate receptors in the cortex with AMPA mediating the fast component ( $2 \mathrm{~ms}$ ) (Kleppe and Robinson, 1999) and NMDA mediating the slow component (190$380 \mathrm{~ms}$ ) (Monyer et al., 1992) of excitatory post-synaptic currents.

The subunits of these receptors affect experience-dependent plasticity. Insertion of the GluR2 subunit into AMPA receptor influences maturation and synaptic plasticity by regulating $\mathrm{Ca}^{2+}$ permeability and facilitating synaptic transmission (Jonas et al., 1994). Furthermore, GluR2 expression increases during development (Herrmann, 1996), and is affected by brief monocular deprivation during the critical period, leading to synaptic depression in the deprived cortex (Heynen et al., 2003).

Activation of NMDA receptors is also a key component in synaptic maturation and plasticity (Monyer et al., 1994; Flint et al., 1997; Roberts and Ramoa, 1999). NMDA receptors form a heteromeric ion channel composed of one obligatory subunit (NR1) combined with one or more NR2(A-D) or NR3 subunits (Monyer et al., 1992). The different NR2 subunits affect the functional and pharmacological properties of the receptor (Kutsuwada et al., 1992). For example, decay of the EPSC speeds up 2-3 fold when NR2A is inserted into the receptor (Flint et al., 1997). In addition, a number of studies have shown that a blockade of the NMDA receptor reduces ocular dominance plasticity (Kleinschmidt et al., 1987; Bear et al., 1990; Roberts et al., 1998) and stunts the maturation of orientation selectivity (Ramoa et al., 2001). During development there is a shift in the composition of the NMDA receptor from NR2B to NR2A subunits (Carmignoto and Vicini, 1992; Stocca and Vicini, 1998). That maturational shift occurs during the critical period for ocular dominance plasticity (Roberts and Ramoa, 1999; Chen et al., 2000; Erisir and Harris, 2003; Fagiolini et al., 2003) and decreases the susceptibility to changes in synaptic strength (Quinlan et al., 1999a; Philpot et al., 2001). The NR2B subunit also affects plasticity by limiting AMPA receptor expression at developing synapses (Hall et al., 2007). Experience drives a number of changes in AMPA receptors including increasing GluR2 expression after monocular TTX (Gainey et al., 2009) and changing the phosphorylation state of GluR1 and GluR2 subunits causing reduced visual evoked potentials (Heynen et al., 2003).

On the inhibitory side, $\mathrm{GABA}_{\mathrm{A}}$ receptors are the dominant ionotropic inhibitory receptors in visual cortex, conducting $\mathrm{Cl}^{-}$ions leading to hyperpolarization of the neuronal membrane. $\mathrm{GABA}_{\mathrm{A}}$ is a heteromeric receptor comprised of subunits from at least eight distinct families; $\alpha(1-6), \beta(1-3), \gamma(1-3), \delta, \varepsilon, \pi, \Theta, \sigma$ (Bonnert et al., 1999; Whiting et al., 1999). Although the composition of GABA receptors varies, the majority of $\mathrm{GABA}_{\mathrm{A}}$ receptors are composed of $2 \alpha, 2 \beta$, and $1 \gamma$ subunits (Araujo et al., 1996; Sieghart et al., 1999). $\mathrm{GABA}_{\mathrm{A}}$ receptor composition changes during development from more $\mathrm{GABA}_{\mathrm{A}} \alpha 2$ and $\mathrm{GABA}_{\mathrm{A}} \alpha 3$ to more GABA $\mathrm{A} \alpha 1$, speeding up the kinetics of the receptor (Laurie et al., 1992) and increasing the binding affinity for benzodiazepines (Sieghart, 1992). It is becoming clear that $\mathrm{GABA}_{\mathrm{A}} \alpha 1$ plays a special role in experience-dependent development since $\alpha 1$-containing receptors specifically drive ocular dominance plasticity in the visual cortex (Fagiolini et al., 2004).
Taken together, these studies highlight the central role that excitatory and inhibitory receptor subunits play in mediating experiencedependent development and plasticity in the visual cortex.

Although several studies have shown that an appropriate E/I balance is crucial for experience-dependent changes in visual cortex, few have addressed how early experience affects expression of both excitatory and inhibitory receptors (Heynen et al., 2003; Kanold et al., 2009) and whether changes vary across the representation of the central, peripheral, and monocular visual fields in the cortex (Murphy et al., 2004). These are important questions because experience-dependent changes in NMDA, AMPA, and $\mathrm{GABA}_{\mathrm{A}}$ receptors will affect synaptic plasticity, and the visual and neural deficits in human amblyopes are greatest for the central visual field (Hess and Pointer, 1985; Li et al., 2007). We addressed these questions by quantifying developmental changes for a set of excitatory (NMDA, AMPA) and inhibitory $\left(\mathrm{GABA}_{\mathrm{A}}\right)$ receptor subunits in cat visual cortex after normal vision or monocular deprivation. Monocular deprivation promoted a complex pattern of changes in expression of the receptor subunits. The changes were dependent on age and were most severe in the part of visual cortex representing the central visual field. We applied a neuroinformatics approach using principal components analysis (PCA) to characterize the multidimensional pattern of experience-dependent change in the receptor subunits. Monocular deprivation caused a dramatic change in the developmental trajectory of excitatory and inhibitory receptor subunit expression: bypassing a large portion of the normal developmental path, shifting the E/I balance, and accelerating the maturation of receptor composition.

\section{MATERIALS AND METHODS ANIMALS}

We studied changes in expression of a set of excitatory and inhibitory receptor subunits in the visual cortex of 17 kittens (age 2-32 weeks), reared with either normal visual experience $(n=9)$ or monocular deprivation $(n=8)$ initiated at the time of natural eye opening until either before $(4,5$, or 6 weeks of age) or after ( 9 or 32 weeks of age) the peak of the critical period (Table 1) (Olson and Freeman, 1980). The eyelids were sutured closed with 5-0 vicryl using aseptic surgical techniques, gaseous anesthetic [isoflurane (1.5-5\%) in oxygen] for induction and maintenance of anesthesia, and following procedures that have been described in detail previously (Murphy and Mitchell, 1987). All experimental procedures were approved by the McMaster University Animal Research Ethics Board.

Animals were euthanized (sodium pentobarbital, $165 \mathrm{mg} / \mathrm{kg}$ ), and transcardially perfused with cold $0.1 \mathrm{M}$ phosphate buffered saline (PBS) $\left(4^{\circ} \mathrm{C} ; 80-100 \mathrm{ml} / \mathrm{min}\right)$ until circulating fluid was clear. The brain was quickly removed from the skull and immersed in cold PBS. We collected $12 \mathrm{small}(2 \mathrm{~mm} \times 2 \mathrm{~mm})$ tissue samples from each visual cortex (Figure 1) so that we would be able to quantify differences between the regions of visual cortex where the central, peripheral, and monocular visual fields are represented (Tusa et al., 1978). Each cortical tissue sample was rapidly frozen on dry ice and stored at $-80^{\circ} \mathrm{C}$.

\section{SYNAPTONEUROSOME PREPARATION}

Tissue samples were put in $1 \mathrm{ml}$ of cold homogenization buffer (10 mM HEPES, 1 mM EDTA, 2 mM EGTA, 0.5 mM DTT, 10 mg/l leupeptin, $50 \mathrm{mg} / \mathrm{l}$ soybean trypsin inhibitor, $100 \mathrm{nM}$ microcystin, 
Table 1 |Animal rearing conditions.

\begin{tabular}{|c|c|c|}
\hline \multirow{2}{*}{$\begin{array}{l}\text { Age sacrificed } \\
\text { (in weeks) }\end{array}$} & \multicolumn{2}{|c|}{ Condition } \\
\hline & Normal & $\begin{array}{l}\text { Monocularly deprived } \\
\text { (from eye opening) }\end{array}$ \\
\hline 2 & * & \\
\hline 3 & * & \\
\hline 4 & * & \\
\hline 5 & * & \\
\hline 6 & * & \\
\hline 8 & * & \\
\hline 12 & * & \\
\hline 16 & * & \\
\hline 32 & * & \\
\hline 4 & & $*$ \\
\hline 5 & & $*$ \\
\hline 5 & & $*$ \\
\hline 6 & & * \\
\hline 6 & & * \\
\hline 9 & & * \\
\hline 9 & & $*$ \\
\hline 32 & & $*$ \\
\hline
\end{tabular}

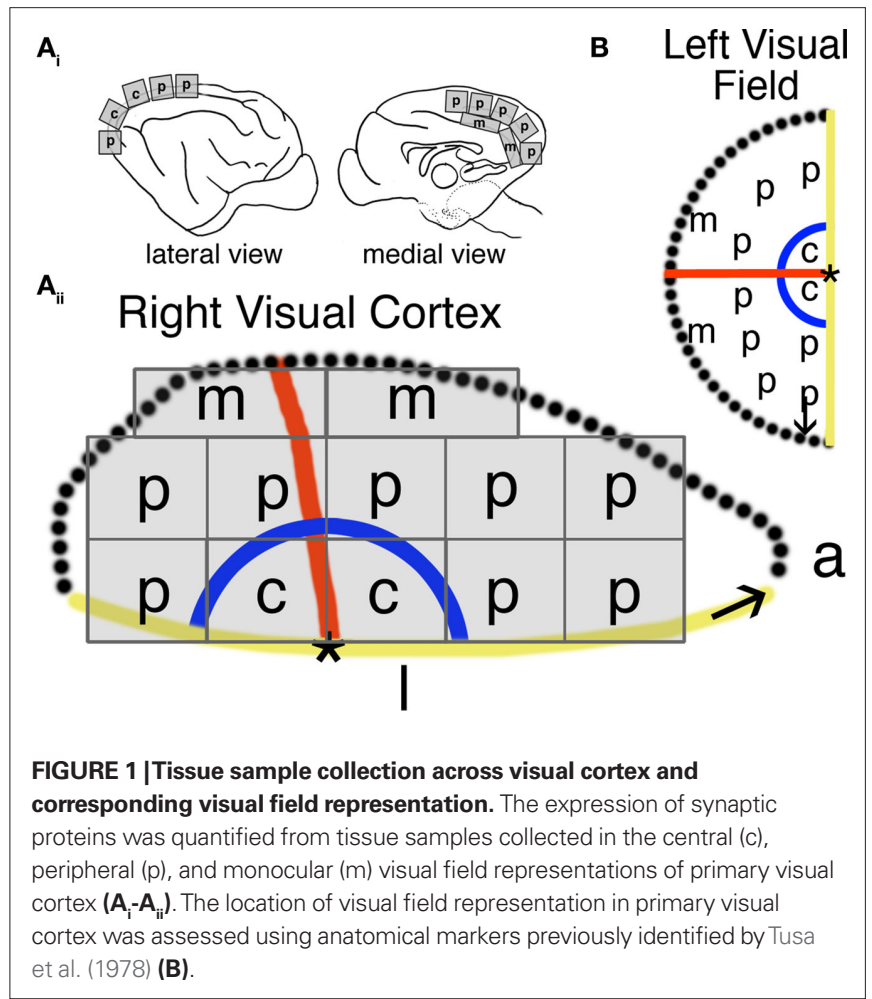

$0.1 \mathrm{mM}$ PMSF) and homogenized in a glass-glass Dounce tissue homogenizer (Kontes, Vineland, NJ, USA). A subcellular fractionation procedure (synaptoneurosomes) (Hollingsworth et al., 1985; Quinlan et al., 1999a) was performed to obtain protein samples that were enriched for synaptic proteins. The synaptoneurosome was obtained by passing the homogenate through a $5-\mu \mathrm{m}$ pore hydrophobic mesh filter (Millipore, Billerica, MA, USA) and centrifuging for $10 \mathrm{~min}$ at $\times 1000 \mathrm{~g}$ to obtain the synaptic fraction of the membrane. The resulting pellet was resuspended in boiling $1 \%$ SDS and stored at $-80^{\circ} \mathrm{C}$. Protein concentrations were determined using the bicinchoninic acid (BCA) assay (Pierce, Rockford, IL, USA). The synaptoneurosome samples were compared with the supernatant and whole homogenate to verify that there was a 2-3fold enrichment for synaptic proteins.

\section{IMMUNOBLOTTING}

We used Western blotting to quantify protein expression. Equal quantities of synaptoneurosome samples $(20 \mu \mathrm{g})$ were resolved on 4-20\% SDS-PAGE gels (Pierce, Rockford, IL, USA) and transferred to polyvinylidine fluoride (PVDF) membranes (Millipore, Billerica, MA, USA). Membranes were blocked in PBS containing 0.05\% Triton X-100 (Sigma, St Louis, MO, USA) (PBS-T) and 5\% skim milk (wt/vol) for $1 \mathrm{~h}$, then incubated in primary antibody overnight at $4^{\circ} \mathrm{C}$ using the following concentrations: NR1 1:2000 (BD Biosciences Pharmingen, San Diego, CA, USA); NR2A 1:2000, NR2B 1:2000 (Chemicon International, Temecula, CA, USA), GluR2 1:1000, Synapsin I 1:4000 (Zymed laboratories, San Francisco, CA, USA); GABA $\alpha 1$ 1:500 (Santa Cruz Biotechnology, Santa Cruz, CA, USA); GABA $_{A} \alpha 3$ 1:2000 (Chemicon International, Temecula, CA, USA). The membranes were incubated in the appropriate secondary antibody conjugated to horseradish peroxidase (HRP) for $1 \mathrm{~h}$ (1:2000; Cedarlane Laboratories, Burlington, ON, USA). Immunoreactivity was visualized using enhanced chemiluminescence (ECL) (Amersham, Pharmacia Biotech, Piscataway, NJ, USA) and exposed to autoradiographic film (X-Omat, Kodak, Rochester, NY, USA). Membranes were stripped using the Blot Restore Membrane Rejuvenation kit (Chemicon International, Temecula, CA, USA) and then re-probed with additional antibodies.

\section{ANALYSIS}

The Western blot bands were quantified using densitometry. The films were scanned (16 bit, AGFA ArcusII, Agfa, Germany) along with an optical density wedge (Oriel Corporation, Baltimore, MD, USA), and the intensities of the bands were converted to optical densities. The background optical density was subtracted from each band, and the band density was quantified using Matlab (The MathWorks, Inc., Natick, MA, USA). All samples were quantified relative to a control sample that was run on each gel. We plotted scattergrams for each antibody and each region of visual cortex (central, peripheral, monocular visual field representation). The plots included the average expression and standard error of the mean (s.e.m.) for each animal and were normalized to the expression of the normal adult central visual field samples. To help describe the developmental pattern of changes in expression, a weighted average curve was fit to each scatter plot using the locally weighted least squares method at $50 \%$.

Changes in NMDA and $\mathrm{GABA}_{\mathrm{A}}$ receptor subunit composition were quantified by calculating four indices: NR2A:NR2B $=[(\mathrm{NR} 2 \mathrm{~A}-\mathrm{NR} 2 \mathrm{~B}) /(\mathrm{NR} 2 \mathrm{~A}+\mathrm{NR} 2 \mathrm{~B})]$; NR1:GluR2 $=[($ NR1 - GluR2 $) /(\mathrm{NR} 1+$ GluR2 $)] ;$ GluR2:NR2B $=[($ GluR2 - NR2B $) /($ GluR2 + NR2B $)]$; and GABA $\alpha 1$ : $\mathrm{GABA}_{\mathrm{A}} \alpha 3=\left[\left(\mathrm{GABA}_{\mathrm{A}} \alpha 1-\mathrm{GABA}_{\mathrm{A}} \alpha 3\right) /\left(\mathrm{GABA}_{\mathrm{A}} \alpha 1+\mathrm{GABA}_{\mathrm{A}} \alpha 3\right)\right]$. 
Statistical comparisons of difference in expression levels between age-matched normal and monocularly deprived animals were performed using Kruskal-Wallis non-parametric analysis of variance and post hoc comparisons were made using Wilcoxon tests. Significant differences reported in the Results section represent comparisons with normal animals.

\section{PRINCIPAL COMPONENT ANALYSIS}

A multivariate analysis of the expression pattern for all synaptic proteins was done using principal component analysis (PCA). The synaptic protein expression was compiled in an $m \times n$ matrix. The $m$ rows represent synaptic proteins (NR1, NR2A, NR2B, GluR2, $\mathrm{GABA}_{\mathrm{A}} \alpha 1, \mathrm{GABA}_{\mathrm{A}} \alpha 3$, Synapsin) for a total of $m=7$, and the $n$ columns represent protein expression levels for each of the 17 animals ( 9 normal, 8 monocularly deprived) and the 3 regions (central, peripheral, monocular) for a total of $n=51$. The data were centered by subtracting the mean column vector, and then a singular value decomposition (SVD) (Matlab, The Mathworks, Inc., Natick, MA, USA) was applied to calculate the principal components. SVD represents the expression level of all proteins from one kitten as a vector in high dimensional space. The principle component analysis identifies the direction in "protein expression space" that represents the variance in the data across all conditions. When plotted as a 3-dimensional representation of this space, clusters of data near each other, or that are ordered along the same dimension, have similar attributes or classification (Marder and Goaillard, 2006; Taylor et al., 2006). This method provides a useful representation of higher dimensional patterns and similarities among a set of genes or proteins, allowing quantification of global pattern in large data sets.

In this study, the first three components of the PCA analysis accounted for $85 \%$ of the variance. To determine potential biological links for the three principal components, we calculated correlations between the each principal component and the synaptic protein expression levels and indices. The significance level for identifying potential biological correlates was adjusted to $p<0.007$ using the Bonferroni correction for multiple comparisons. The PCA results were visualized in 3-dimensions using custom software and a ray-tracing program (Radiance; Ward, 1994).

\section{RESULTS}

We evaluated the experience-dependent expression of NR1, NR2A, NR2B, GluR2, GABA $\alpha 1, G_{A} A_{A} \alpha 3$, and Synapsin in normally reared $(n=9)$ and monocularly deprived cats $(n=8)$ using multiple samples from across primary visual cortex. First, we examined whether there were any differences in total synaptic expression between age-matched normal and deprived animals by comparing expression of the pre-synaptic marker Synapsin. We found no differences in the level of Synapsin expression between normal and age matched monocularly deprived animals up to 9 weeks of age or adult $(p>0.05)$, indicating that deprivation did not cause a generalized loss of pre-synaptic expression. The next section presents analyses of the changes in expression for each of the receptor subunits from samples representing the central, peripheral, and monocular visual fields in visual cortex. The following sections present analyses of the relative balance between excitatory and inhibitory receptor expression and an analysis of the global pattern of changes that characterizes the normal developmental trajectory and differences caused by monocular deprivation.

\section{EXCITATORY RECEPTOR SUBUNIT EXPRESSION Normal development}

In normal kittens, there were substantial developmental changes in the expression of NR1, NR2A, NR2B, and GluR2 (Figure 2) (open symbols). These subunits were expressed at low levels shortly after eye opening ( 2 weeks of age), increased 3-8-fold to reach maximum expression levels by 8 weeks, and then decreased substantially to near adult levels by 16 weeks. Adult levels of expression were similar to those found in young animals ( $<6$ weeks of age) and very similar across each of the three regions in visual cortex. There were regional differences in expression of NR1 and NR2A in the normal animals. For NR1 and NR2A, expression in the central visual field representation remained high until 12 weeks of age before dropping to adult levels. The most striking regional difference was found for NR2A expression in the monocular region where normal animals did not show an increase in NR2A expression after 5 weeks of age (Figure 2F). Between 6 and 12 weeks of age, NR2A expression in the monocular region was significantly lower than in the other two regions $(p<0.01)$.

\section{Monocular deprivation}

In monocularly deprived kittens, the developmental profile of NR1, NR2A, NR2B, and GluR2 expression in visual cortex was significantly different from normal. There were both age-related and regional changes in the expression levels of NMDA and AMPA receptor subunits in monocularly deprived animals (Figure 2, filled symbols). Furthermore, there were clear difference in the expression between shorter $(<6$ weeks of age) and prolonged ( $>6$ weeks of age) deprivation.

Deprivation to 4,5 , or 6 weeks of age led to changes in expression of the glutamate receptors subunits, however, not all regions were affected equally (Figure 3 ). In the central visual field region (red bars), there was significantly less NR1 $(p<0.01)$, NR2A $(p<0.01)$, NR2B $(p<0.05)$ and GluR2 $(p<0.05)$ than found in normal animals (Figures 3A-D). In the peripheral visual field region (green bars), there was less NR2A ( $p<0.05)$ but no change in NR1, NR2B, or GluR2. In the monocular region (black bars), there was a significant increase in NR1 $(p<0.05)$ expression, but no change in NR2A, NR2B, or GluR2. The regional pattern of NR1 changes is in good agreement with our previous study using NR1 immunohistochemistry on unfolded and flattened cortical sections that found less NR1 expression in the central region and an increase in the monocular region (Murphy et al., 2005). The regional changes found here for NR1, NR2A, NR2B, and GluR2 expression show that the effects of abnormal visual experience are not uniform across visual cortex and that during the peak of the critical period (4-6 weeks of age) the central visual field region is more vulnerable to experiencedependent changes.

Extending monocular deprivation beyond 6 weeks of age led to substantial changes in expression of the glutamate receptors subunits (Figure 2). Longer deprivation either prevented the normal increase or led to significantly less expression than normal animals. The animals deprived to 9 weeks of age had 2-5 times 


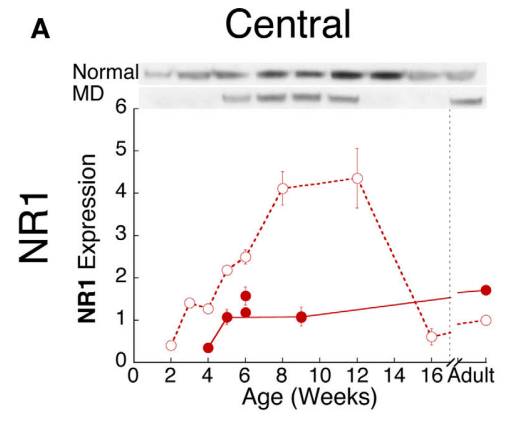

D

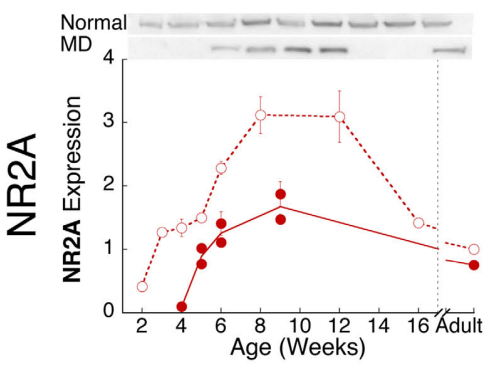

G

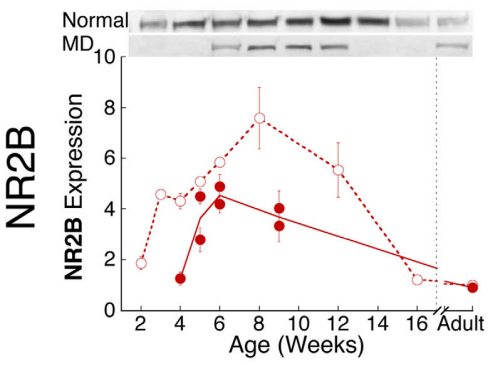

$\mathbf{J}$

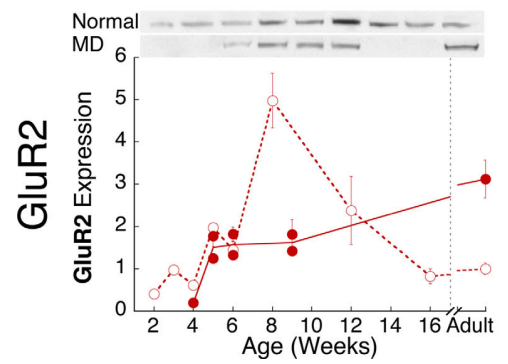

B

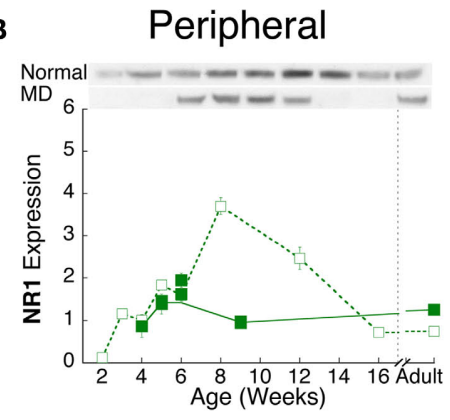

E

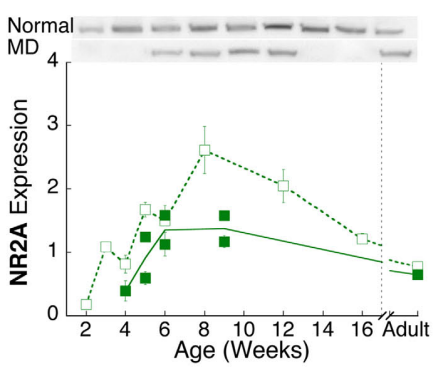

H

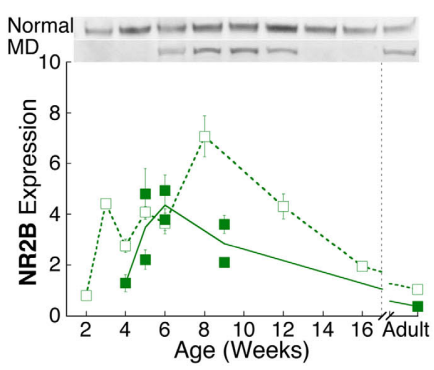

K

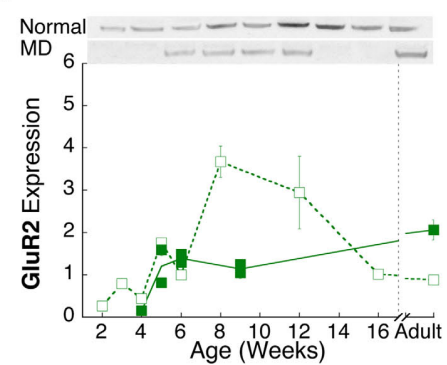

C

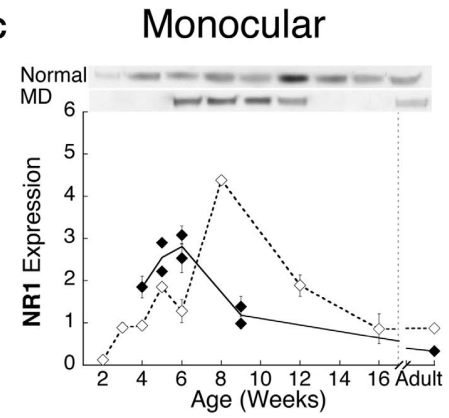

$\mathbf{F}$

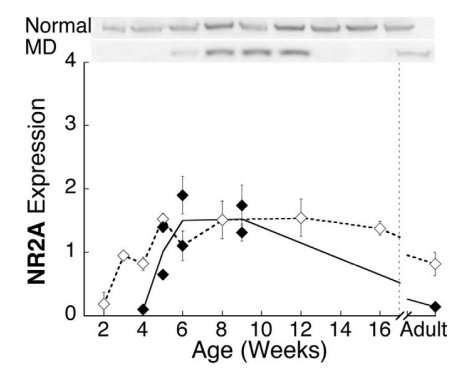

I

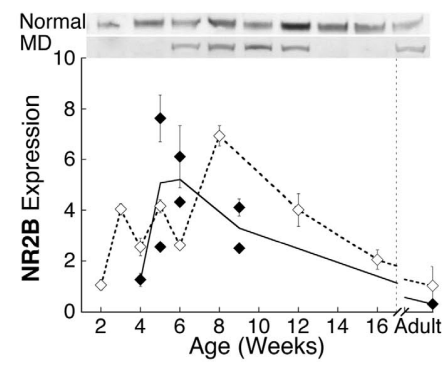

$\mathbf{L}$

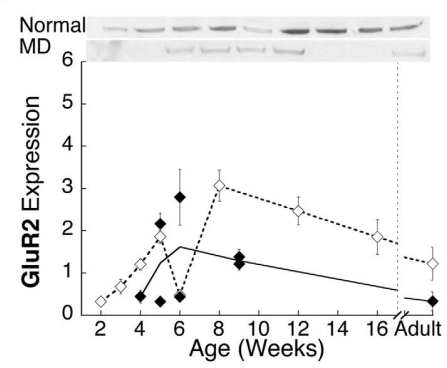

FIGURE 2 | Experience-dependent changes in NMDA and AMPA receptor subunit expression. Comparison of excitatory receptor subunits NR1 (A-C), NR2A (D-F), NR2B (G-I) and GluR2 (J-L) in normal (open symbols, dashed lines) and monocularly deprived (filled symbols, solid lines) kittens from the central (red circles), peripheral (green squares) and monocular (black diamonds) visual field representations during postnatal development. For each subunit, the plots were normalized relative to the average normal adult expression in the central visual field. Error bars indicate the s.e.m. Representative Western blot bands are shown above each plot. less expression than normal animals (Figure 2) $(p<0.01)$. There was one notable exception to this pattern, NR2A expression in the monocular region was similar between normal and deprived animals (Figure 2F). The relatively large difference of these receptor subunits after prolonged ( $>6$ weeks of age) versus shorter $(<6$ weeks of age) deprivation suggests that multiple processes underlie the effects of monocular deprivation on expression of these excitatory synaptic components. One process may affect early development by shifting expression so that it is different from but parallels normal development, while another process affects later development leading to a large deviation from the normal trajectory and substantially less glutamatergic subunit expression.

\section{RELATIVE EXPRESSION OF NMDA AND AMPA SUBUNITS IS ALTERED BY DEPRIVATION}

Key functional properties of the glutamate receptor are determined by the relative expression of NMDA and AMPA receptor subunits. Specifically, an increase of NR2A relative to NR2B is part of the normal 


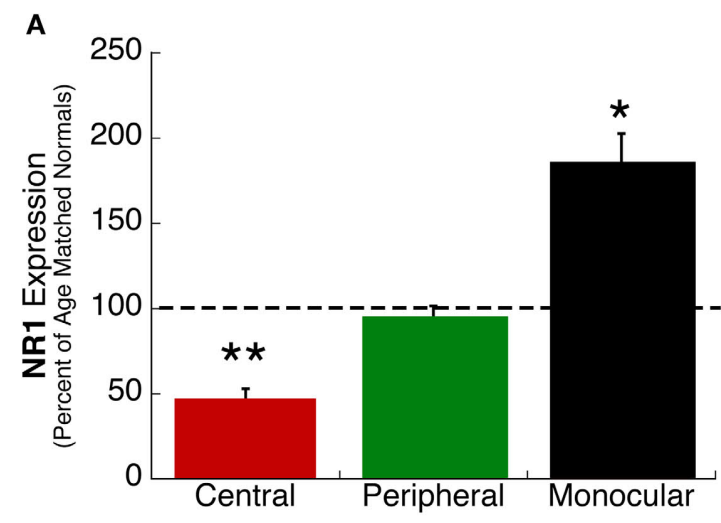

B

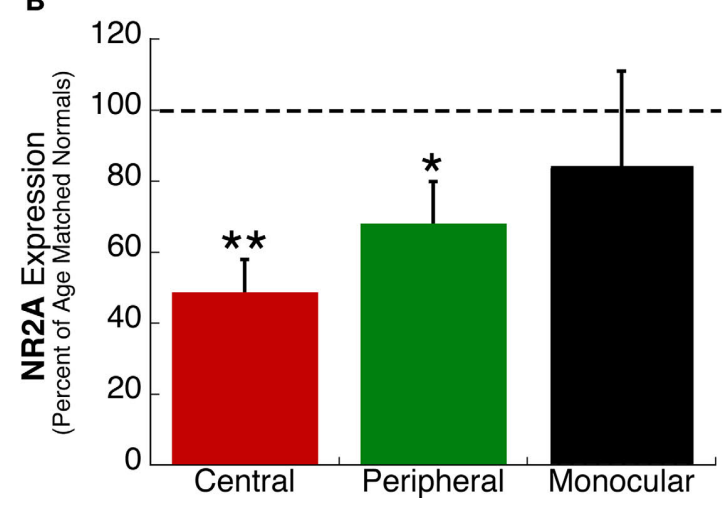

FIGURE 3 | Regional changes in the expression of excitatory receptor subunits (A) NR1, (B) NR2A, (C) NR2B, and (D) GluR2 in kittens monocularly deprived up to 6 weeks of age. The expression in the central (red), peripheral (green), and monocular (black) visual field representation

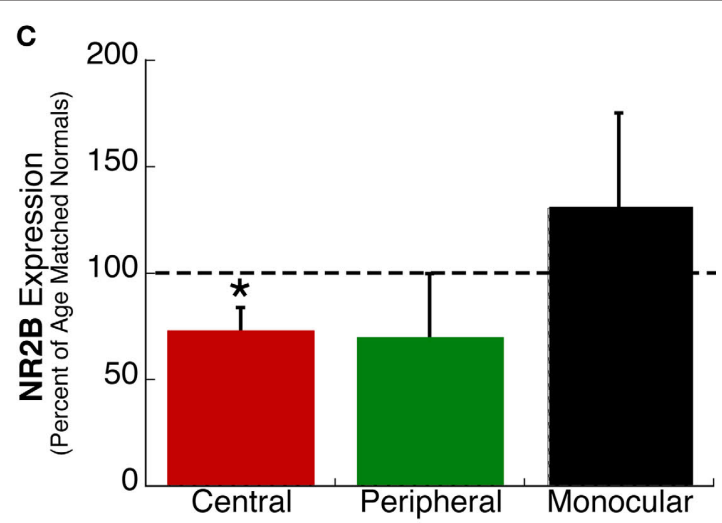

D

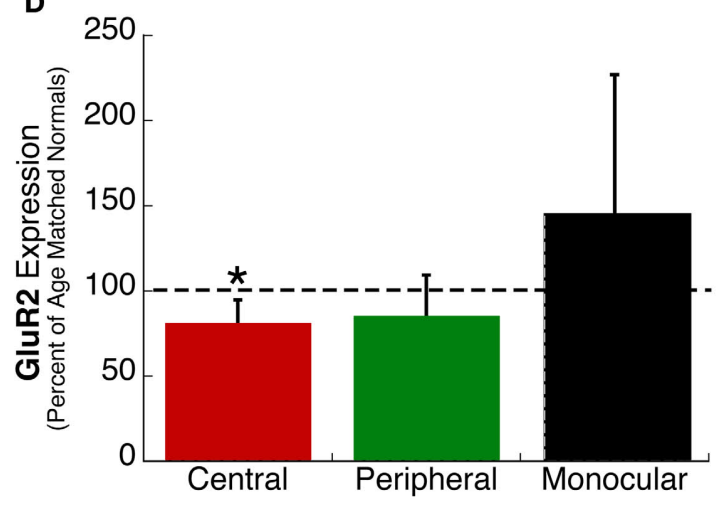

was measured as a percent of age matched normal kittens for each region of visual cortex. Dashed lines represent the relative expression in normally reared kittens. Significant differences are indicated ${ }^{*} p<0.05$; $\left.{ }^{* *} p<0.01\right)$.

was initially 3-5 fold higher than adult levels and remained high until after 8 weeks of age when there was a steady decline to reach adult levels by 16 weeks of age (Figures $5 \mathrm{~A}-\mathrm{C}$ ). The changes in $\mathrm{GABA}_{A} \alpha 3$ were similar for the three regions of visual cortex. Expression of $\mathrm{GABA}_{\mathrm{A}} \alpha 1$ followed a different developmental pattern and there were regional differences. $G_{A B A} \alpha 1$ was initially low ( 2 weeks of age) and increased during the first 4 weeks for peripheral and monocular regions and during the first 8 weeks for the central region, after which expression declined to reach adult levels by 16 weeks of age (Figures 5E,F). The largest developmental increase in $\mathrm{GABA}_{\mathrm{A}} \alpha 1$ expression was found in the central visual field region where expression increased almost 3 -fold between 2 and 8 weeks of age (Figure 5D). This increase in $\mathrm{GABA}_{A} \alpha 1$ expression in the central region of normal visual cortex (Figure 5D) was similar to patterns found for NMDA and AMPA subunits (Figure 2).

\section{Monocular deprivation}

There were substantial changes in $\mathrm{GABA}_{\mathrm{A}} \alpha 3$ and $\mathrm{GABA}_{\mathrm{A}} \alpha 1$ expression following monocular deprivation (Figure 5) (filled symbols). In monocularly deprived kittens, $\mathrm{GABA}_{\mathrm{A}} \alpha 3$ expression was reduced to about half the normal level of expression $(p<0.01)$ and that level was similar in the central, peripheral, and monocular visual field regions. Quite a different pattern of change was found for $\mathrm{GABA}_{\mathrm{A}} \alpha 1$ expression. Shorter monocular deprivation $(<6$ weeks 

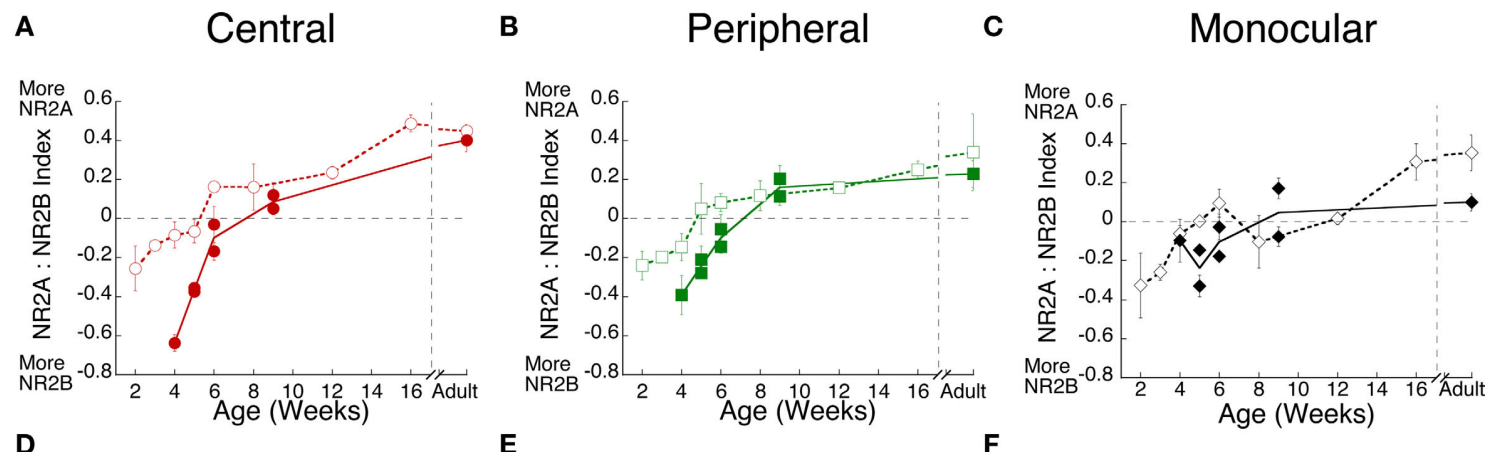
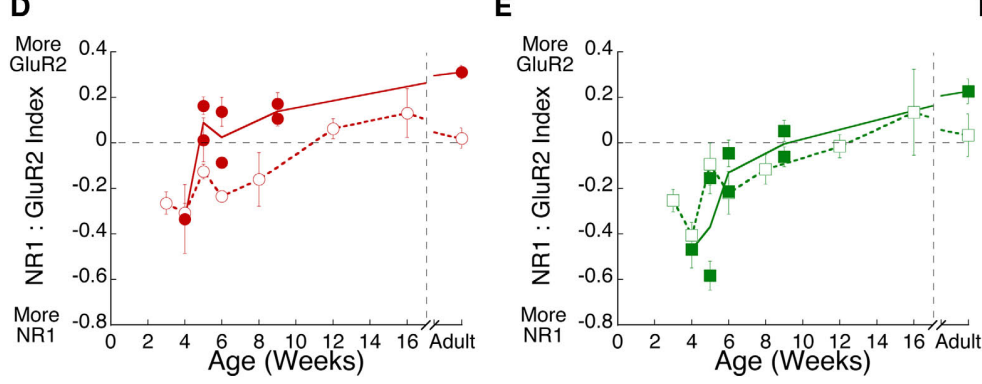

G

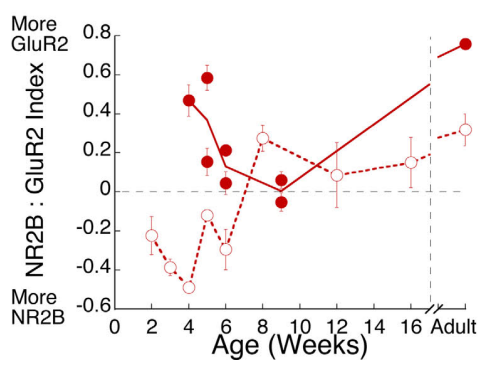

$\mathbf{H}$

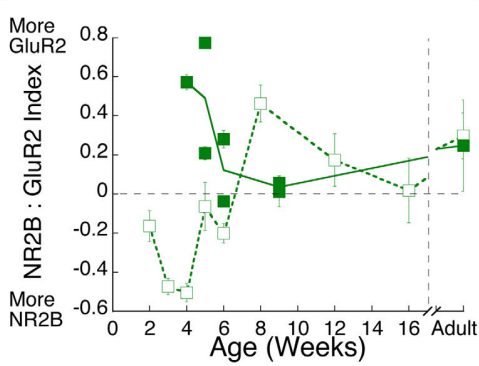

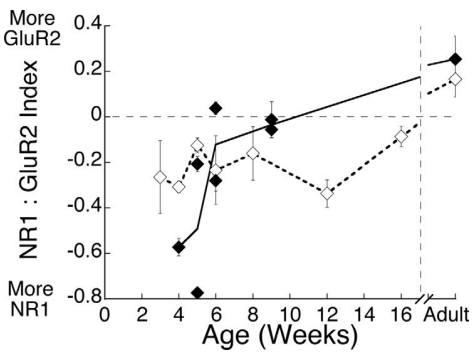

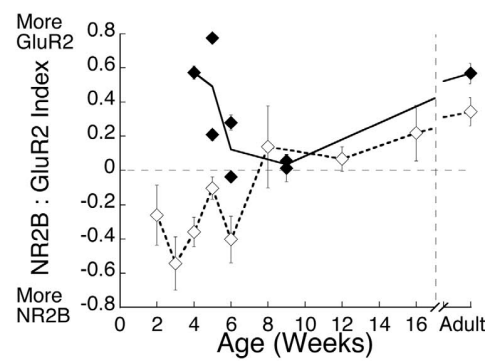

FIGURE 4 | Monocular deprivation shifts the maturation of receptor subunit composition. Experience-dependent maturation of the (A-C) NR2A:NR2B, (D-F) NR1:GluR2, and (G-I) NR2B:GluR2 indices was quantified for normal (open symbols, dashed lines) and monocularly deprived (filled symbols, solid lines) kittens. Monocular deprivation affected each of the indices. It delayed the shift to NR2A, but accelerated the shift to GluR2. of age) led to a significant increase in $\mathrm{GABA}_{\mathrm{A}} \alpha 1$ expression in central and peripheral regions (Figures 5D,E, $p<0.05$ ), while prolonging deprivation to 9 weeks of age led to less $\mathrm{GABA}_{\mathrm{A}} \alpha 1$ expression (Figure 5F, $p<0.05$ ). In contrast with the NR1 and NR2A that we greatest in the central visual field region, the $\mathrm{GABA}_{\mathrm{A}}$ subunit changes were similar across the visual cortex (Figure 5). The difference in $\mathrm{GABA}_{\mathrm{A}} \alpha 1$ expression between shorter ( $<6$ weeks) and prolonged ( $>6$ weeks) monocular deprivation provides additional support for the idea that multiple developmental processes underlie the experience-dependent changes in receptor expression in visual cortex.

\section{MONOCULAR DEPRIVATION ACCELERATES THE SWITCH TO GABA $\alpha 1$}

We quantified changes in the relative expression of the $\mathrm{GABA}_{\mathrm{A}}$ receptor subunits in visual cortex of normal and monocularly deprived kittens because GABA receptor function is affected by the composition of the receptor and $\mathrm{GABA}_{A} \alpha 1$ plays a specific role in ocular dominance plasticity (Figures 6A-C). In normal kittens (open symbols), the shift from $\mathrm{GABA}_{A} \alpha 3$ to $\mathrm{GABA}_{\mathrm{A}} \alpha 1$ in visual cortex was similar across the three regions, changing from more $\mathrm{GABA}_{\mathrm{A}} \alpha 3$, to roughly balanced expression between 4 and
12 weeks expression, and finally substantially more $\mathrm{GABA}_{\mathrm{A}} \alpha 1$ expression by 16 weeks of age. Monocular deprivation led to a very different developmental profile for the relative expression of $\mathrm{GABA}_{A} \alpha 1$ and $\mathrm{GABA}_{A} \alpha 3$ (Figure 6, filled symbols). There was significantly more $\mathrm{GABA}_{A} \alpha 1$ relative to $\mathrm{GABA}_{A} \alpha 3$ during development in deprived animals $(p<0.01)$. Monocular deprivation promoted a premature switch to relatively more $\mathrm{GABA}_{\mathrm{A}} \alpha 1$ in visual cortex (Figure 6).

\section{MONOCULAR DEPRIVATION DISRUPTS THE EXCITATORY-INHIBITORY BALANCE}

To quantify the E/I balance, we analyzed the relative expression of the excitatory and inhibitory receptor subunits by comparing the expression of the three indices. First, we examined the relationship between the NR2A:NR2B and GABA $_{A} \alpha 1: G_{B B} \alpha 3$ indices for both normal and monocularly deprived animals (Figure 7). For normal animals (Figures 7A-D), there were strong correlations between these indices for all three regions (central $r=0.96$, $p<0.01$; peripheral $r=0.88, p<0.01$; monocular $r=0.79, p<0.01$ ) as well as for all of visual cortex $(r=0.78, p<0.01)$. These results show a tight relationship in the expression of these excitatory and 


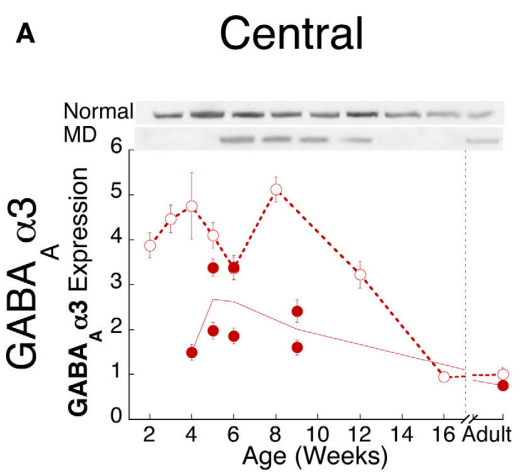

D

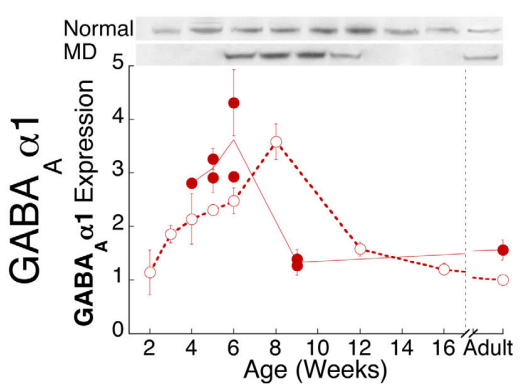

B

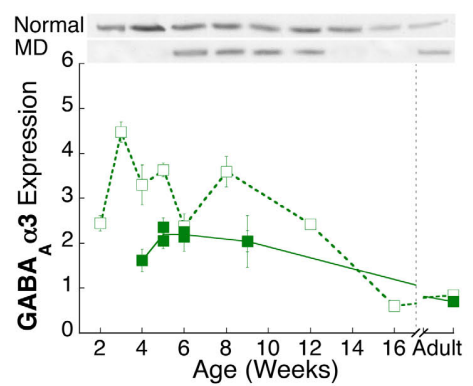

E

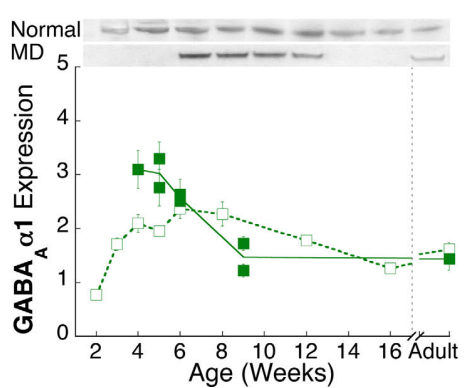

c Monocular

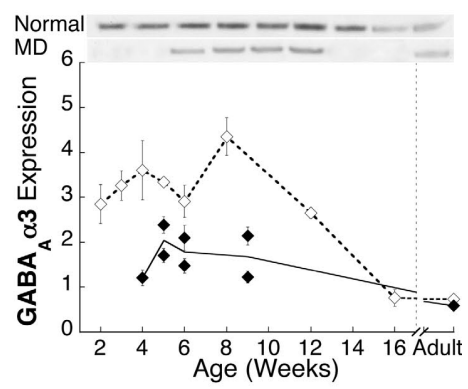

$\mathbf{F}$

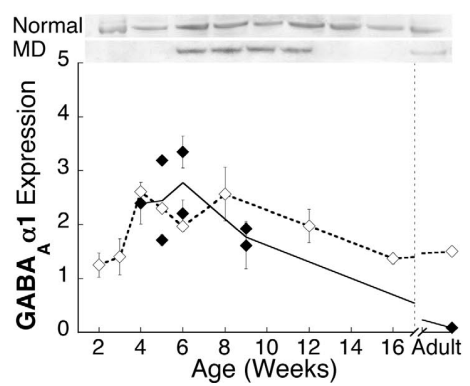

FIGURE 5 | Experience-dependent changes in GABA ${ }_{A}$ receptor subunit expression. Comparison of $\mathrm{GABA}_{A} \alpha 3(\mathbf{A}-\mathbf{C})$ and $\mathrm{GABA}_{\mathrm{A}} \alpha 1$ (D-F) subunit expression in normal (open symbols, dashed lines) and monocularly deprived (filled symbols, solid lines) kittens from the central (red circles), peripheral (green squares) and monocular (black diamonds) visual field representations during postnatal development. For each subunit, the plots were normalized relative to the average normal adult expression in the central visual field. Error bars indicate the s.e.m.. Representative Western blot bands are shown above each plot.

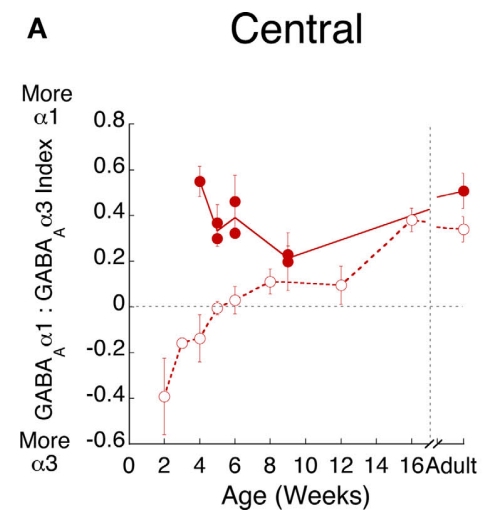

B

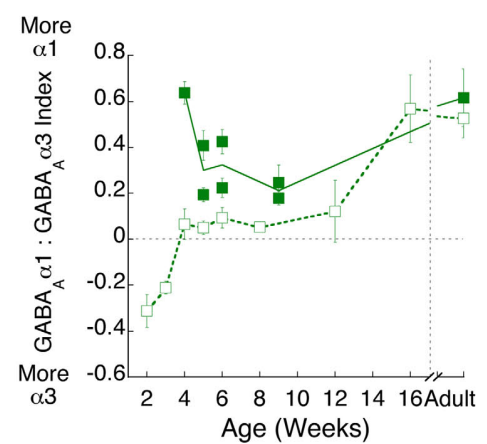

c

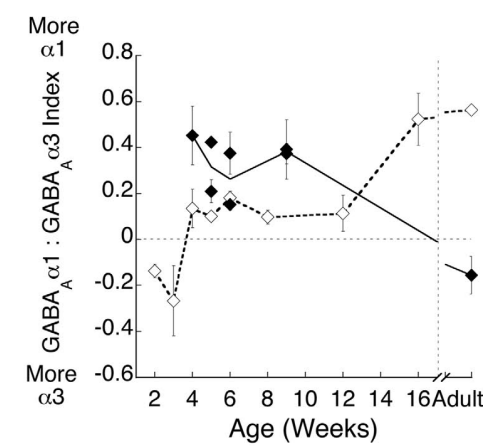

FIGURE 6 | Monocular deprivation accelerates the switch to $\mathrm{GABA}_{A} \boldsymbol{\alpha 1}$. Experience-dependent maturation of the $\mathrm{GABA}_{\mathrm{A}} \alpha 1: \mathrm{GABA}_{\mathrm{A}} \alpha 3$ index was quantified in normal (open symbols, dashed lines) and monocularly deprived (filled symbols, solid lines) kittens in the (A) central (red circles), (B) peripheral (green squares), and (C) monocular (black diamonds) visual field representations. inhibitory receptor subunits in normal animals: when there was more NR2B there was also more $\mathrm{GABA}_{\mathrm{A}} \alpha 3$ expression, and when there was more NR2A there was more $\mathrm{GABA}_{\mathrm{A}} \alpha 1$. A very different picture emerged in monocularly deprived animals (Figures 7E-H). There were no significant correlations between the NR2 and GABA indices. Monocular deprivation caused a profound changed in the balance between the NR2 and GABA receptor subunits. The same pattern was found when we analyzed the relationship between the NR2B:GluR2 and $\mathrm{GABA}_{A} \alpha 1: \mathrm{GABA}_{\mathrm{A}} \alpha 3$ indices (Figure 8).
In normal animals there was a strong relationship between the expression of these receptor subunits (central $r=0.75 p<0.025$, peripheral $r=0.65 p<0.05$, monocular $r=0.77 p<0.01$, overall $r=0.62 p<0.01$ ). That relationship was lost in monocularly deprived animals where there were no correlations between the NR2B:GluR2 and GABA $\alpha 1: G_{A B A} \alpha 3$ indices. Together, these results show that normally there is an exquisite balance in the expression of these excitatory and inhibitory subunits but that balance is lost after monocular deprivation. 


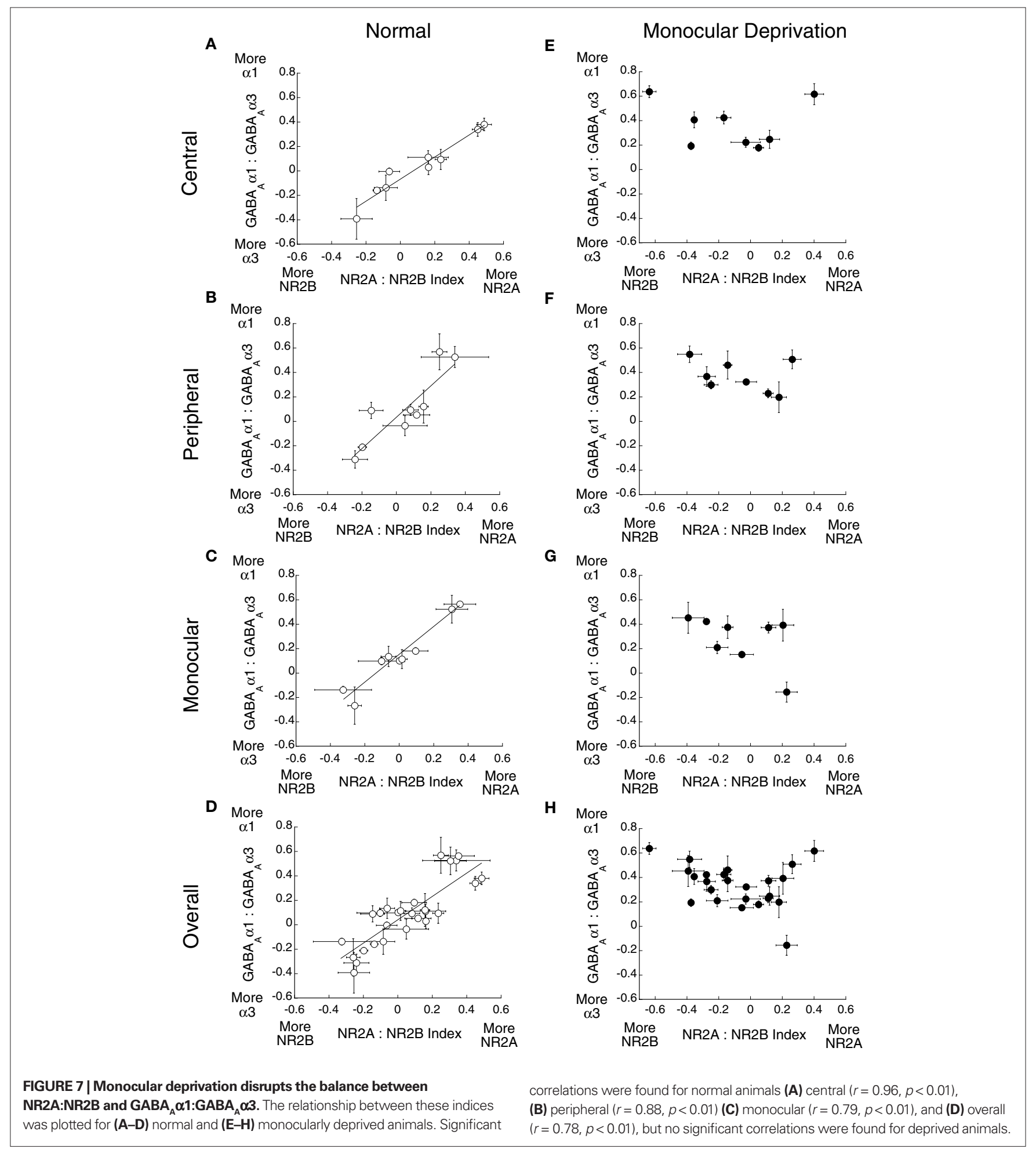

PRINCIPAL COMPONENTS ANALYSIS

It is clear from the present findings that there is a complex pattern of change in the expression of these excitatory and inhibitory receptor subunits in the developing visual cortex. This is similar to gene expression (Majdan and Shatz, 2006; Tropea et al., 2006) and proteomic studies showing that visual experience drives a complex pattern of up- and down-regulation of genes in visual cortex (Van den Bergh et al., 2006). Together, this work underscores the importance of studying multiple mechanisms to gain new insights into factors that influence cortical development. The complex nature of these changes, however, presents a challenge for quantifying and understanding global patterns of 


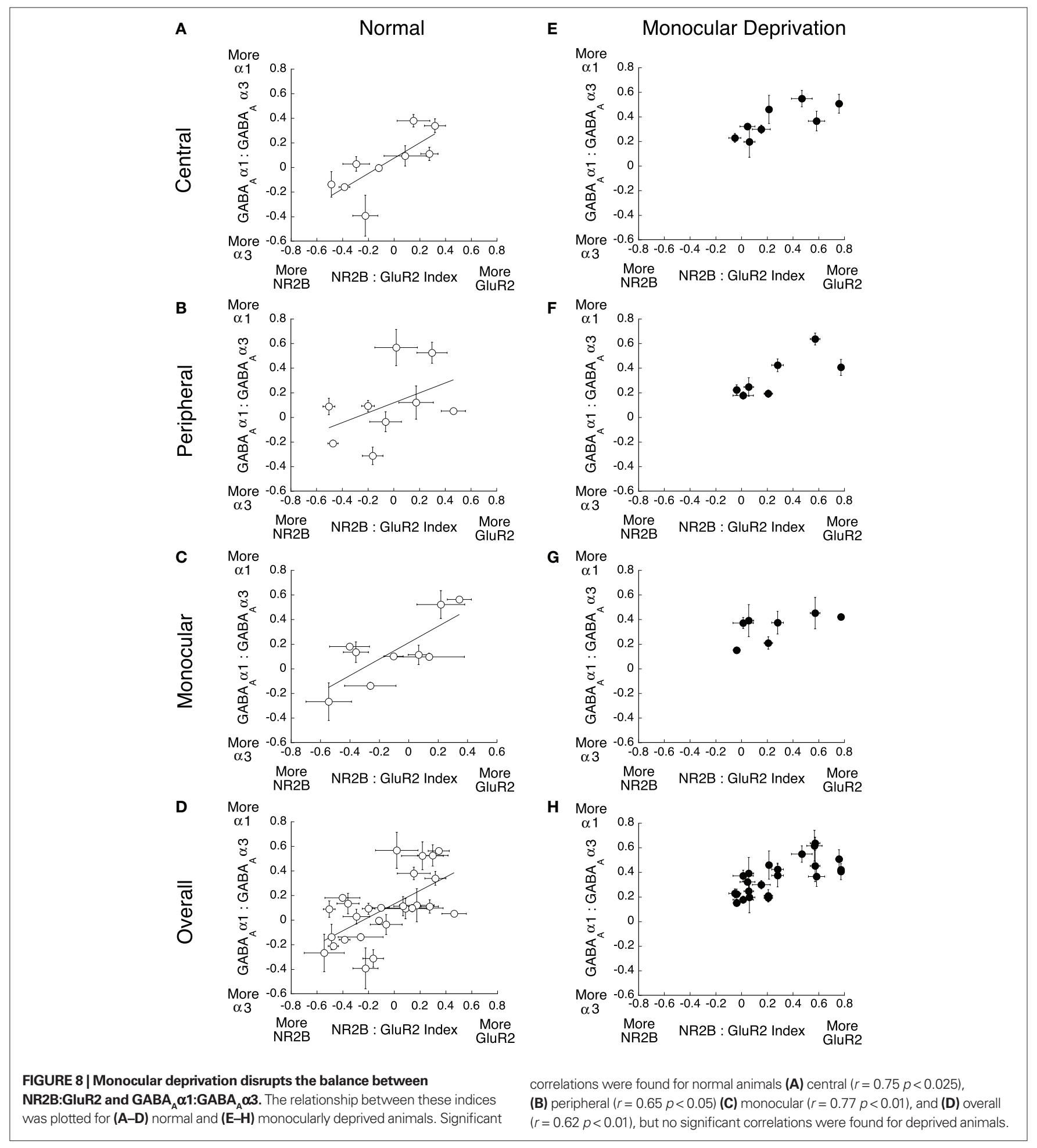

experience-dependent development. We addressed the complex nature of the experience-dependent changes in subunit expression using a data-driven approach and analyzed the pattern of synaptic protein expression in kitten visual cortex using singular value decomposition (SVD) to quantify the principal components. The SVD showed that the first principal component explained the greatest proportion of the variance $(57 \%)$

(Figure 9A). The second principal component explained 19\% and the third component describes $9 \%$ of the variance. Beyond the third component (components 4-7), gradually less of the variance was explained (6-2\% respectively). Since the first three principal components accounted for $85 \%$ of the variance these were determined to be the significant components of the SVD (Everitt and Dunn, 1991). 

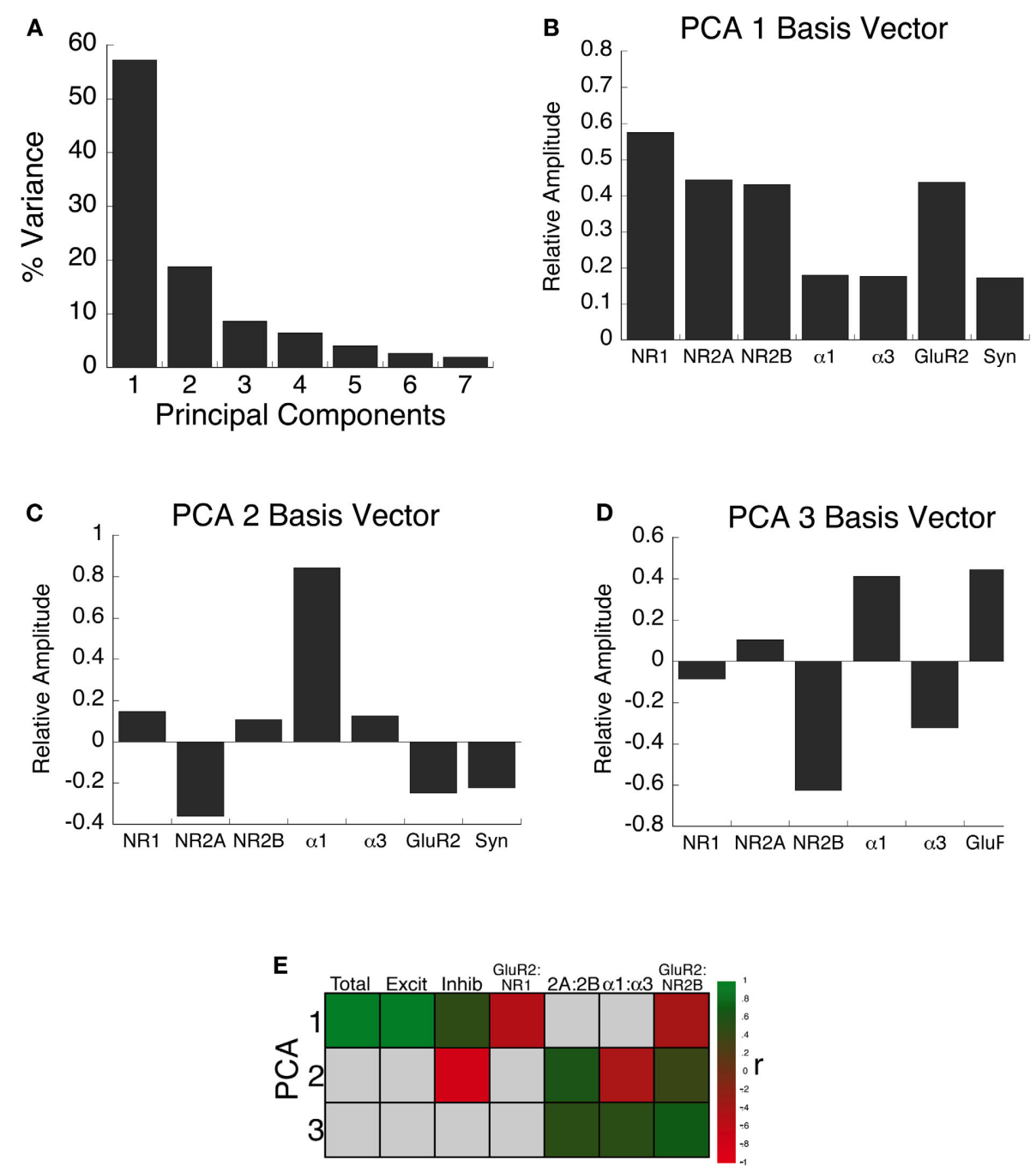

FIGURE 9 | Principal component analysis. (A)The percent of variance captured by each component from SVD analysis of receptor subunit expression in visual cortex of normal and monocularly deprived kittens. The first three principal components represent the significant portion (85\%) of the SVD. (B-D)The influence of each subunit on the three principal components was reflected by the relative amplitudes in the basis vectors. (E) Significant correlations (colored cells) between the three principal components and the combinations of receptor subunit expression derived from the basis vectors (see Results). The color indicates the magnitude (represented by color intensity) and direction (green indicates positive, red indicates negative) of significant correlations (Bonferroni corrected, $p<0.007$ ).
Each component of the SVD represents a linear combination of the expression levels of the excitatory and inhibitory receptor subunits. The influence that each subunit had on each of the principal components was reflected by the relative amplitude in the basis vectors. Evaluating the basis vectors is an important step in the analysis that we added to link the principle components with potential biological mechanisms. This two step process, computing the principle components and correlating the basis vectors with receptor expression, provides novel insights into the pattern of receptor expression.

Figures 9B-D shows the basis vectors for the three principal components, illustrating the direction and magnitude for each of the seven synaptic proteins. The first principal component (Figure 9B, PCA 1), showed positive contributions from all mechanisms, with the greatest from the excitatory receptors. The second component (Figure 9C, PCA 2), showed clear differences in the direction and magnitude of the contributions of excitatory and inhibitory receptor subunits with the largest difference between the relative amplitude of NR2A and GABA $\alpha 1$. The third principal component (Figure 9D, PCA 3) showed opposite directions for biologically relevant pairs of receptor subunits: NR2A-NR2B, GABA $_{\mathrm{A}} \alpha 1-\mathrm{GABA}_{\mathrm{A}} \alpha 3$, GluR2-NR1, and GluR2-NR2B.

Simply calculating the principal components, however, does not directly address the biological factors that influence each of the principal components. To begin to relate the principal components to potential biological mechanisms, we generated a set of correlations based on combinations of factors suggested by the basis vectors in Figures 9B-D. Some combinations were examined separately in the previous sections (NR2A:NR2B, GABA $\alpha 1$ :GABA $\alpha 3$, GluR2:NR1, GluR2:NR2B), while the others were new (total protein expression, excitatory expression, inhibitory expression). Figure $9 \mathrm{E}$ shows the 
significant correlations (green and red squares; $p<0.007$ ) between these factors and the three principal components. The pattern of correlations provided information to describe the biological significance of the principal components. The first principal component was characterized by a significant increase in the total expression of receptor subunits, and a shift from NMDA to AMPA expression. The second principal component captured the developmental balance between excitatory and inhibitory receptor subunit expression. Finally, the third principal component captured the maturation of subunit expression in visual cortex shifting to more GABA $\alpha 1$, NR2A, and GluR2.

To visualize the three significant principal components, the data were plotted in 3-dimensional space using custom software and a ray-tracing program (Radiance; Ward, 1994). Figure 10 shows the
PCA results for normal (gold spheres) and monocular deprived kitten (red cubes), and the connecting lines link the points by age. These plots showed distinct developmental trajectories for normal and monocularly deprived animals (supplemental videos of developmental trajectories available on-line). The shadows projected on each of the three walls help to visualize the differences between normal (circles) and deprived (squares) kittens.

\section{Normal development}

The normally reared kittens (Figure 10A, gold spheres and lines) showed a developmental trajectory that was an elongated, U-shaped function, extending along PCA 1 (total expression) from 2 to 8 weeks of age, and then turning back to reach the adult

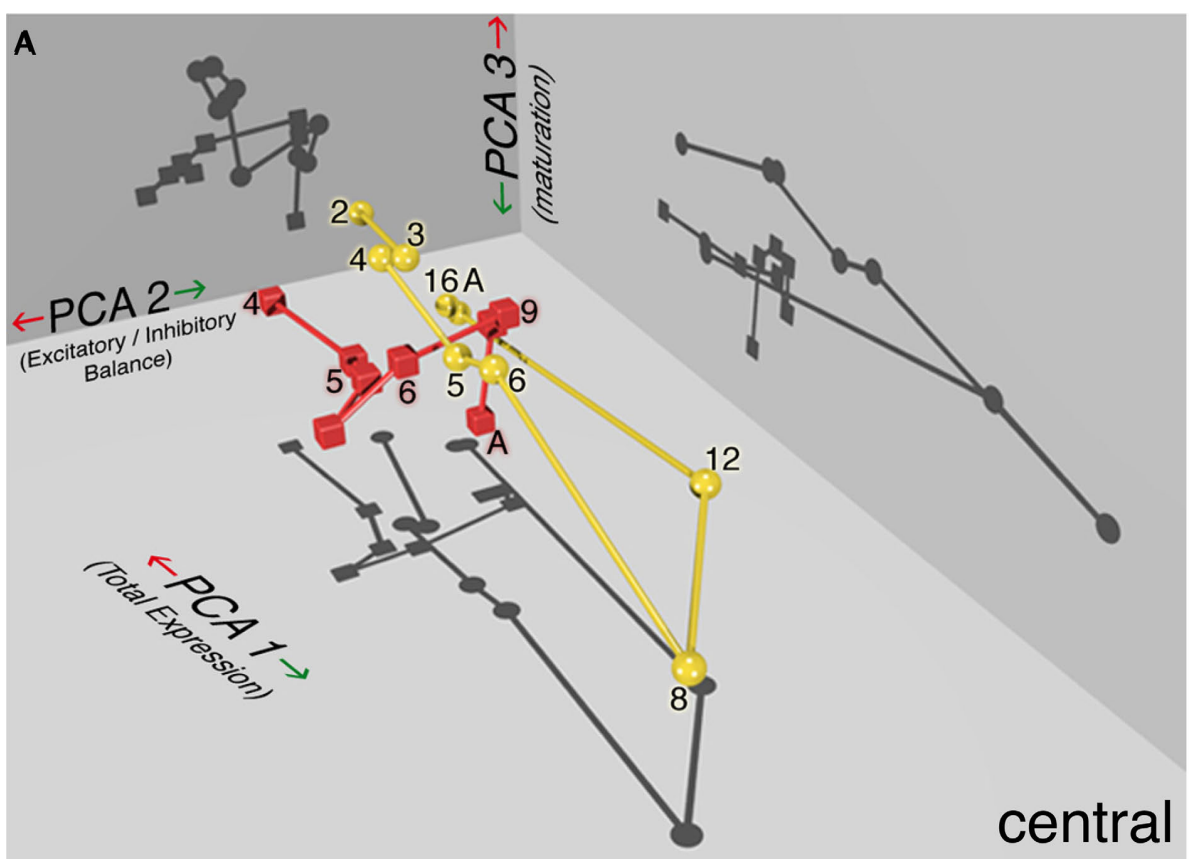

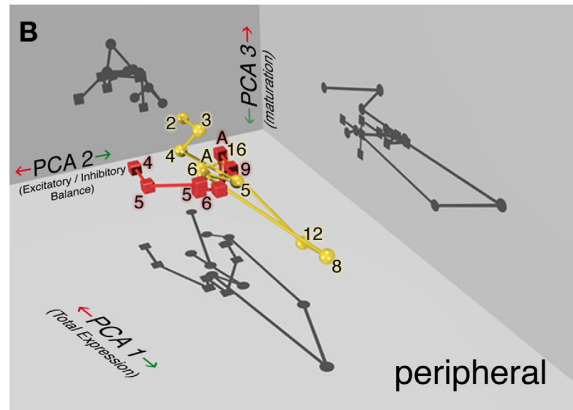

FIGURE 10 | Monocularly deprived animals show a distinct developmental trajectory for receptor subunit expression. The PCA results are plotted in 3-dimensions to visualize the significant components for normal (yellow spheres) and monocularly deprived (red cubes) kittens in the (A) central, (B) peripheral, and (C) monocular visual field representation of visual cortex. The shadows projected on each of the three walls help to visualize the differences between normal (circles) and deprived (squares) kittens for each of the three components. Age (in weeks) is displayed beside each symbol and the connecting lines link the points by age. PCA 1 captures experience-dependent changes in total receptor subunit expression, PCA 2 captures changes in the E/I balance and PCA 3

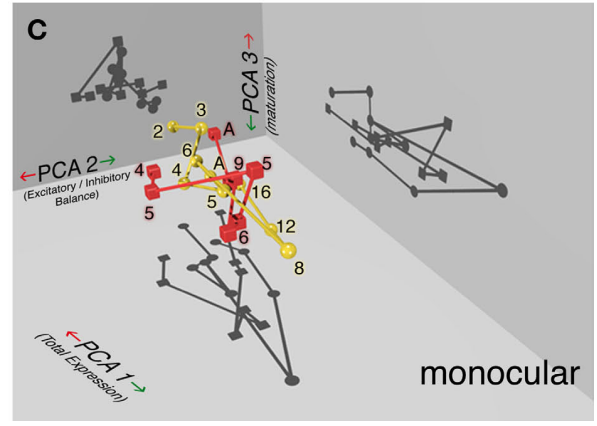

captures the maturation of receptor composition. The developmental trajectory for normal animals (yellow sphere, circle shadows) can be described as a slowly descending curved staircase that traversed a long direction of increasing expression (PCA 1) and slow maturation of receptor subunits (PCA 3) between 2 and 8 weeks of age followed by turning a corner to a new E/I balance (PCA 2) at 12 weeks and pruning back the total receptor expression by 16 weeks. The trajectory for deprived kittens (red cubes, square shadows) was shifted on all three dimensions and truncated from the normal pattern. The difference between normal and deprived kittens was greatest for the (A) central visual field and less for the (B) peripheral and (C) monocular regions. 
location. It is important to note that the age of the animals was not part of the analysis and yet there was an orderly, age-dependent, developmental trajectory through this space. The component of PCA 2 (E/I balance), seen best in the shadow projected on the wall, remains fixed between 2 and 8 weeks of age, then jumped across at 12 weeks of age to a new point that was maintained in adulthood. This suggest that in normal kittens, the balance between excitation and inhibition changes rapidly between 8 and 12 weeks of age. Finally, there was a gradual change in PCA 3 (receptor subunit maturation) between 2 and 8 weeks of age in the direction of more mature receptor subunit expression. Overall, the developmental trajectory for normal animals can be described as a slowly descending curved staircase that initially traversed a long direction of increasing expression and slow maturation of receptor subunits followed by turning a corner to a new E/I balance and pruning back the total receptor expression.

\section{Monocular deprivation}

A very different developmental trajectory was found when the principal components were plotted for the monocularly deprived animals (red cubes and lines). Initially, monocularly deprived animals followed a trajectory parallel to normals but shifted on PCA 2 and PCA $3(p<0.01)$. The E/I balance, represented by PCA 2 , was shifted from normal and the maturation of receptor subunits, represented by PCA 3, was accelerated in deprived animals. Both of these can be seen in the shadows for PCA 2 and PCA 3. When deprivation was extended beyond 6 weeks of age there was a dramatic change in the developmental trajectory. With longer deprivation ( $>6$ weeks) kittens bypassed a large portion of PCA 1 that represents a stage of exuberant expression of the excitatory and inhibitory receptor subunits. There was also a premature jump to the adult PCA 2 level indicating an abrupt change in the E/I balance. The developmental trajectory for deprived animals was shifted on all 3-dimensions and truncated from the normal pattern. Furthermore, the difference between normal and deprived animals was greatest for the central visual field representation (Figure 10A), and less for the peripheral (Figure 10B) and monocular representations (Figure 10C). The PCA analysis showed that the complex pattern of changes found for individual receptor subunits can be understood as reflecting three underlying processes: reduced total expression of receptor subunits, shifted E/I balance, and accelerated subunit maturation.

\section{DISCUSSION}

Our results show that monocular deprivation triggers a complex pattern of changes in the NMDA, AMPA, and GABA receptor subunits that mediate experience-dependent plasticity in visual cortex. A major finding of this study is that the overall pattern of experiencedependent changes reflects three underlying components with clear biological interpretations. Using a neuroinformatics approach to analyze subunit expression we find that monocular deprivation: (i) changes overall receptor expression so that a large portion of the normal receptor development is bypassed; (ii) shifts the E/I balance in favor of inhibition by decreasing NR1, NR2A, and NR2B but increasing $\mathrm{GABA}_{\mathrm{A}} \alpha 1$; (iii) and accelerates the maturation of subunits to relatively more GluR2 and $\mathrm{GABA}_{A} \alpha 1$. All of these changes are greatest in the central visual field representation of kitten visual cortex. Taken together, these results show that monocularly deprived animals lack the synaptic machinery needed for normal maturation of cortical circuits and developmental plasticity. Furthermore, the changes are more extensive than just disrupting the E/I balance.

\section{RECEPTOR SUBUNIT CHANGES MAY AFFECT SPECIFIC CORTICAL CIRCUITS}

Each of the excitatory and inhibitory receptor subunits that we studied were changed by monocular deprivation. These results extend the work of a recent study (Kanold et al., 2009) aimed at unifying ideas about excitatory and inhibitory contributions to experiencedependent plasticity in the visual cortex. Although many prior experiments have measured changes in receptor expression after early monocular deprivation, few have examined both excitatory and inhibitory subunits (e.g., Heynen et al., 2003; Kanold et al., 2009) or compared the changes across the visual cortex (Murphy et al., 2004). We combine these approaches using Western blotting and then applied PCA to uncover the major components affecting experience-dependent development of receptor subunit expression in visual cortex. Furthermore, the subunits we examined are linked with the functional properties of NMDA and GABA $\mathrm{A}_{\mathrm{A}}$ receptors (Flint et al., 1997; Bosman et al., 2002) and the susceptibility to various forms of synaptic plasticity (Quinlan et al., 1999a; Fagiolini et al., 2003; Heinen et al., 2004). The Western blot approach, however, did not allow us to address laminar or circuit changes in visual cortex which would be best characterized by anatomical or physiological approaches that can resolve finer details of cortical organization. For example, $\mathrm{GABA}_{\mathrm{A}} \alpha 1$ subunits are preferentially localized at synapses on the soma of pyramidal neurons receiving input from fast spiking inhibitory inter-neurons (Mohler, 1992; Nusser et al., 1996; Fritschy and Brunig, 2003). This circuit is affected by monocular deprivation during the critical period, strengthening an inhibitory feedback loop in layer 4 and thus reducing excitability (Maffei et al., 2006, 2010). Since GABAergic inhibition directly onto the soma can regulate the timing and synchrony of action potentials (Miles et al., 1996; Klausberger et al., 2003; Chattopadhyaya et al., 2004), a change to this circuit will have a profound impact on cortical development and function that depends on the precise timing between excitatory and inhibitory neurotransmission. The increase in $\mathrm{GABA}_{\mathrm{A}} \alpha 1$ expression that we found after monocular deprivation is suggestive of changes in the circuit that includes fast spiking interneurons and pyramidal neurons. But this cannot be the only circuit in kitten visual cortex affected by monocular deprivation. The changes in NMDA and AMPA subunits that we found may contribute to laminar specific changes in LTD, similar to those reported for rodent visual cortex (Cozier et al., 2007; Cho et al., 2009). Importantly, the reduced NR2A expression in deprived kittens may shift the LTD/LTP threshold in layer 4 in favor of potentiation and lead to precocious strengthening of the open eye's inputs (Cho et al., 2009). The current results provide a good foundation to direct future studies aimed at mapping laminar and cellular changes in visual cortical circuits that are affected by early visual deprivation.

\section{EFFECTS OF MONOCULAR DEPRIVATION ARE GREATEST IN THE CENTRAL VISUAL FIELD REPRESENTATION}

Although the visual and neural deficits in human amblyopia are greatest in the central visual field (Hess and Pointer, 1985; Li et al., 2007), few studies have examined regional changes in the 
mechanisms that underlie these functional losses. Physiological studies of amblyopic macaque monkeys have shown that the greatest receptive field changes occur for neurons in the central visual field representation in the visual cortex (Kiorpes et al., 1998). In a previous study, we showed that monocular deprivation reduces NR1 expression in the part of visual cortex where the central visual field is represented (Murphy et al., 2004). Here, we found that in addition to less NR1, the changes in NR2A, NR2B, GluR2, and $\mathrm{GABA}_{\mathrm{A}} \alpha 1$ are also greatest in the central visual field. Furthermore, the PCA analysis showed that the greatest difference between normal and deprived animals was in the central region, with less and less difference in peripheral and monocular regions.

These regional changes may reflect differences in the relative contributions of binocular competition (Hebbian plasticity) and monocular compensation (synaptic scaling) toward regulating experience-dependent plasticity. This raises the possibility that the changes in receptor expression are driven by binocular competition in the central visual field, binocular competition and synaptic scaling in the peripheral visual field, and only synaptic scaling in the monocular visual field. This is similar to previous studies in developing mouse visual cortex showing that monocular deprivation reduces the deprived eye responses in binocular neurons but increases responses for neurons that receive input from only the deprived eye (Mrsic-Flogel et al., 2007). These bidirectional plasticity results provide evidence that functional demands can engage different types of experiencedependent plasticity. The current findings provide a potential synaptic basis for the greater central versus peripheral visual field losses found in amblyopes. They also highlight that animal models with a well developed central visual field provide an important contribution to understanding the neural basis of amblyopia.

\section{MONOCULAR DEPRIVATION BYPASSES A LARGE PORTION OF NORMAL RECEPTOR DEVELOPMENT}

A striking consequence of monocular deprivation was that a large portion of the normal developmental trajectory was bypassed. In normal animals, we found a transient stage of exuberant receptor expression between 6 and 16 weeks of age which is after the peak of ocular dominance plasticity in kittens (Olson and Freeman, 1980). When monocular deprivation extended past 6 weeks of age, we found that the stage of exuberant receptor subunit expression was bypassed. Our finding of a normal stage of exuberant expression is similar to previous reports for NMDA (Chen et al., 2000) and GABA subunits (Chen et al., 2001) showing that the maximum expression level in kitten visual cortex is reached after the peak of ocular dominance plasticity. The notion of early exuberance in synapse development followed by a plateau in synaptic density (Bourgeois and Rakic, 1993; Bourgeois et al., 1994) or gradual elimination are a common views about cortical development (Huttenlocher et al., 1982; O'Kusky and Colonnier, 1982). In the cat, however, early studies of synaptogenesis using electron microscopy to quantify synaptic density did not examine animals between 6 and 16 weeks of age (Cragg, 1975), and thus missed the time window when receptor subunit expression peaks in cat visual cortex. In addition, there have been few physiological studies of synaptic or receptive field maturation in visual cortex of kittens between 6 and 16 weeks of age. The lack of information between 6 and 16 weeks of age makes it challenging to link the normally exuberant expression of receptor subunits with specific developmental changes. There have been, however, a number of behavioral studies of visual development that overlap with the period of receptor subunit exuberance and those studies have shown that visual functions, such as grating acuity, vernier acuity, and binocular functions are maturing at that time (Timney, 1981; Mitchell, 1989; Murphy and Mitchell, 1991). Furthermore, visual recovery is substantially less when monocular deprivation extends beyond 6 weeks of age (Giffin and Mitchell, 1978; Mitchell, 1988). The abrupt change in the developmental trajectory of subunit expression for deprived animals coincides with the age when physiological studies of ocular dominance plasticity in kittens have shown that there is a shift to less functional recovery after early monocular deprivation (Blakemore and Van Sluyters, 1974; Movshon, 1976). It seems likely that the differences in expression of the NMDA, AMPA, and $\mathrm{GABA}_{\mathrm{A}}$ subunits found when monocular deprivation ends before versus after the peak of the critical period will have different effects on synaptic plasticity, and thereby contribute to the different capacities for visual and ocular dominance recovery. The nature of orientation plasticity is also distinct before versus after the peak of the critical period (Tanaka et al., 2009). Exposure to a single orientation before the peak of the critical period causes an expansion of that orientation in the cortical map, however, exposure after the peak causes a shift away from that orientation. Taken together, the behavioral and physiological results point to different plasticity mechanisms before versus after the peak of the critical period and the lack of exuberant receptor expression may be a fundamental component underlying poor recovery after longer deprivation.

\section{MONOCULAR DEPRIVATION CHANGES THE E/I BALANCE}

Normally, excitatory and inhibitory circuits interact to stabilize the E/I balance (Le Roux et al., 2006). This exquisite control of synaptic integration is widely accepted as a major factor regulating experiencedependent plasticity in the visual cortex (Fagiolini et al., 2003; Heinen et al., 2004; Turrigiano and Nelson, 2004; Hensch and Fagiolini, 2005; Maffei and Turrigiano, 2008a; Kanold et al., 2009). Even small changes to either excitation or inhibition disrupt responses and alter plasticity in the developing visual cortex (Kirkwood and Bear, 1994; Hensch et al., 1998; Fagiolini et al., 2003; Heynen et al., 2003; Maffei et al., 2010). The current results show that the balance between excitatory and inhibitory receptor subunits is dramatically changed by monocular deprivation. Deprivation up to the peak of the critical period caused less expression of NMDA receptor subunits but an increase in $\mathrm{GABA}_{A} \alpha 1$. Together, these shift the $\mathrm{E} / \mathrm{I}$ balance in favor of inhibition. Prolonging deprivation past the peak caused a premature jump to the adult E/I balance. Clearly, monocular deprivation does not simply co-regulate expression of these receptor subunits to maintain a set $\mathrm{E} / \mathrm{I}$ balance. Instead, deprivation drives the system to a new $\mathrm{E} / \mathrm{I}$ balance, one that must alter the timing of visual cortical circuits and normal spike time-dependent plasticity (Caporale and Dan, 2008). These changes in receptor subunit expression show that experience drives dynamic interactions between excitatory and inhibitory circuits and these changes undoubtedly contribute to the abnormal development of visual cortical circuits.

A recent study by Kanold et al. (2009) has begun to provide a unified view of the excitatory and inhibitory contributions to experience-dependent development of the visual cortex. They found that application of benzodiazepines to rescue ocular dominance 
plasticity in GAD65 knockout mice also increases NR2A expression. Thus, manipulating one side of the E/I balance also affects mechanisms on the other side. Ultimately, these interactive E/I changes regulate activity in the visual cortex and affect experience-dependent plasticity. Perhaps restoring the normal E/I balance by promoting expression of NMDA, AMPA, and $\mathrm{GABA}_{\mathrm{A}}$ receptor subunits to the levels found during early development may be an essential component for good recovery after monocular deprivation. In addition, future studies will need to address presynaptic changes, such as neurotransmitter levels and vesicular transporters that are known to affect synaptic plasticity.

Restoring the E/I balance as a way of improving recovery is not a new idea; recent studies have shown that pharmacological manipulation of the E/I balance in adult visual cortex can reinstate ocular dominance plasticity (Maya Vetencourt et al., 2008; Harauzov et al., 2010). Although our results and other studies point toward both excitatory and inhibitory changes with deprivation during the critical period (Kameyama et al., 2010), it is still an open question whether one side of the E/I balance has a greater impact on experience-dependent plasticity. Two recent studies, however, identify experience-dependent changes in fast spiking GABAergic neurons that depend on the timing of deprivation and can bidirectionally shift the E/I balance (Yazaki-Sugiyama et al., 2009; Maffei et al., 2010). Furthermore, compelling results suggest that young GABAergic neurons may be sufficient to support experience-dependent plasticity. Indeed, transplantation of immature GABA neurons into adult visual cortex induces ocular dominance plasticity (Southwell et al., 2010), suggesting that maturation of GABAergic neurons may provide a critical component of the E/I balance regulating experience-dependent plasticity.

\section{PREMATURE EXPRESSION OF AN ADULT-LIKE PATTERN OF RECEPTOR SUBUNITS}

Developmental changes in the expression of receptor subunits mediate synaptic plasticity in visual cortex (Fagiolini et al., 2003; Philpot et al., 2003; Malenka and Bear, 2004) and have been linked with starting or ending the critical period (Roberts and Ramoa, 1999; Chen et al., 2000, 2001; Erisir and Harris, 2003). The normal shift from more NR2B to more NR2A and GluR2 changes the timing of excitatory neural transmission (Flint et al., 1997), affects second messenger signaling (Strack and Colbran, 1998), alters the threshold for synaptic modifications (Quinlan et al., 1999a; Quinlan et al., 1999b; Philpot et al., 2001), and regulates synaptic scaling (Wierenga et al., 2005; Gainey et al., 2009). Similarly, for GABA receptors, the shift to greater expression of the $\alpha 1$ subunit is necessary for ocular dominance plasticity (Fagiolini et al., 2004). We found that monocular deprivation affected the maturation of these subunit ratios, but not all changed in the same direction. There was a delay in the shift from NR2B to NR2A, but an acceleration in the shift to more GluR2 and $\mathrm{GABA}_{\mathrm{A}} \alpha 1$. Furthermore, our PCA analysis showed that the accelerated shifts accounts for more of the variance in our data, suggesting

\section{REFERENCES}

Antonini, A., and Stryker, M. P. (1993). Rapid remodeling of axonal arbors in the visual cortex. Science 260, 1819-1821.
Araujo, F., Tan, S., Ruano, D., Schoemaker, H., Benavides, J., and Vitorica, J. (1996). Molecular and pharmacological characterization of native cortical gamma-aminobutyric acidA recep-

that monocular deprivation causes the premature expression of an adult-like pattern of subunits. These results underscore the importance of examining multiple receptor subunits, since looking at only one pair of subunits does not give the whole picture. Interestingly, the changes in receptor subunits found for GAD65 knockout mice [an increase in NR2A and no change in $\mathrm{GABA}_{\mathrm{A}} \alpha 1$ expression (Kanold et al., 2009) ], are different from those for monocularly deprived kittens and thus provides another model to tease apart the roles and interactions among the various excitatory and inhibitory mechanisms during development of the visual cortex.

At a functional level, the premature shift to an adult-like pattern of receptor subunits could leave the developing visual cortex in a less plastic state. This accelerated maturation of plasticity mechanisms would help to explain why visual recovery after early monocular deprivation is often poor and not permanent (Murphy and Mitchell, 1986, 1987). In that situation, when vision is restored, they lack the necessary synaptic mechanisms to engage experiencedependent refinement of visual cortical circuits. Another possibility is that the accelerated subunit expression leads to changes in the types of synaptic plasticity that are active during the critical period and these drive abnormal development. For example, the increase in GluR2 may reflect synaptic scaling to compensate for reduced visually drive activity (Gainey et al., 2009); the increase in GABA $\alpha 1$ may accelerate the stage of ocular dominance plasticity (Fagiolini et al., 2004); and the reduced NR2A expression may drive precocious development of the non-deprived eye's inputs (Cho et al., 2009). These physiological changes could both increase the strength of abnormally driven activity and effectively shorten the critical period for activity to influence refinement of cortical circuits. This scenario would lead to the rapid development of abnormal circuits in visual cortex. The current results suggest a combination of both less synaptic plasticity and accelerated maturation of cortical circuits underlying the poor visual recovery after monocular deprivation.

Our findings offer a comprehensive picture of the experiencedependent changes for both excitatory and inhibitory receptor subunits in developing visual cortex. Furthermore, the application of PCA provides novel insights into the pattern of changes induced by deprivation and how it deviates from the normal developmental trajectory. These changes are more extensive than just shifting the $\mathrm{E} / \mathrm{I}$ balance and it will be important to determine the functional significance of bypassing a stage of normal receptor development and prematurely expressing an adult-like pattern. Clearly, multiple synaptic mechanisms are changed by abnormal visual experience and an exciting possibility is that restoring the normal immature pattern of receptor expression by drugs, patching therapy, or visual training may the key to reinstating developmental plasticity and promoting good visual recovery.

\section{ACKNOWLEDGMENTS}

This research was supported by grants from NSERC and CIHR to Kathryn Murphy and David Jones.

tors containing both alphal and alpha3 subunits. J. Biol. Chem. 271, 27902-27911.

Bear, M. F., Kleinschmidt, A., Gu, Q. A., and Singer, W. (1990). Disruption of experience-dependent synaptic modifications in striate cortex by infusion of an NMDA receptor antagonist. J. Neurosci. 10, 909-925. 
Blakemore, C., and Van Sluyters, R. C. (1974). Reversal of the physiological effects of monocular deprivation in kittens: further evidence for a sensitive period. J. Physiol. 237, 195-216.

Bonnert, T. P., McKernan, R. M., Farrar, S., le Bourdelles, B., Heavens, R. P., Smith, D. W., Hewson, L., Rigby, M. R., Sirinathsinghii, D. J., Brown, N., Wafford, K.A., and Whiting,P.J.(1999). Theta, a novel gamma-aminobutyric acid type A receptor subunit. Proc. Natl. Acad. Sci. U.S.A. 96, 9891-9896.

Bosman, L. W., Rosahl, T. W., and Brussaard, A. B. (2002). Neonatal development of the rat visual cortex: synaptic function of GABAA receptor alpha subunits. J. Physiol. 545, 169-181.

Bourgeois, J.P., Goldman-Rakic, P.S., and Rakic, P. (1994). Synaptogenesis in the prefrontal cortex of rhesus monkeys. Cereb. Cortex 4, 78-96.

Bourgeois, J. P., and Rakic, P. (1993). Changes of synaptic density in the primary visual cortex of the macaque monkey from fetal to adult stage. $J$. Neurosci. 13, 2801-2820.

Caporale, N., and Dan, Y. (2008). Spike timing-dependent plasticity: a Hebbian learning rule. Annu. Rev. Neurosci. 31, 25-46.

Carmignoto, G., and Vicini, S. (1992). Activity-dependent decrease in NMDA receptor responses during development of the visual cortex. Science 258, 1007-1011.

Chattopadhyaya, B., Di Cristo, G., Higashiyama, H., Knott, G. W., Kuhlman, S. J., Welker, E., and Huang, Z. J. (2004). Experience and activitydependent maturation of perisomatic GABAergic innervation in primary visual cortex during a postnatal critical period. J. Neurosci. 24, 9598-9611.

Chen, L., Cooper, N. G., and Mower, G. D. (2000). Developmental changes in the expression of NMDA receptor subunits (NR1, NR2A, NR2B) in the cat visual cortex and the effects of dark rearing. Brain Res. Mol. Brain Res. 78, 196-200.

Chen, L., Yang, C., and Mower, G. D. (2001). Developmental changes in the expression of $\mathrm{GABA}(\mathrm{A})$ receptor subunits (alpha(1), alpha(2), alpha(3)) in the cat visual cortex and the effects of dark rearing. Brain Res. Mol. Brain Res. 88, 135-143.

Cho, K. K., Khibnik, L., Philpot, B. D., and Bear, M.F. (2009). The ratio of NR2A/B NMDA receptor subunits determines the qualities of ocular dominance plasticity in visual cortex. Proc. Natl. Acad. Sci. U.S.A. 106, 5377-5382.

Cozier, Y. C., Palmer, J. R., Horton, N. J., Fredman, L., Wise, L. A., and Rosenberg,L. (2007). Relation between neighborhood median housing value and hypertension risk among black women in the United States. Am. J. Public Health 97, 718-724.

Cragg, B. G. (1975). The development of synapses in the visual system of the cat. J. Comp. Neurol. 160, 147-166.

Erisir, A., and Harris, J. L. (2003). Decline of the critical period of visual plasticity is concurrent with the reduction of NR2B subunit of the synaptic NMDA receptor in layer 4. J. Neurosci. 23, 5208-5218.

Everitt, B.S., and Dunn, G. (1991). Applied Multivariate Data Analysis. London: Edward Arnold.

Fagiolini, M., Fritschy, J. M., Low, K., Mohler, H., Rudolph, U., and Hensch, T. K. (2004). Specific GABAA circuits for visual cortical plasticity. Science 303, 1681-1683.

Fagiolini, M., and Hensch, T. K. (2000). Inhibitory threshold for criticalperiod activation in primary visual cortex. Nature 404, 183-186.

Fagiolini, M., Katagiri, H., Miyamoto, H., Mori, H., Grant, S. G., Mishina, M., and Hensch, T. K. (2003). Separable features of visual cortical plasticity revealed by $N$-methyl-D-aspartate receptor 2A signaling. Proc. Natl. Acad. Sci. U.S.A. 100, 2854-2859.

Flint, A. C., Maisch, U. S., Weishaupt, J. H., Kriegstein, A. R., and Monyer, H. (1997). NR2A subunit expression shortens NMDA receptor synaptic currents in developing neocortex. $J$. Neurosci. 17, 2469-2476.

Fritschy, J. M., and Brunig, I. (2003). Formation and plasticity of GABAergic synapses: physiological mechanisms and pathophysiological implications. Pharmacol. Ther. 98, 299-323.

Gainey, M.A., Hurvitz-Wolff, J.R., Lambo, M. E., and Turrigiano, G. G. (2009). Synaptic scaling requires the GluR2 subunit of the AMPA receptor. $J$. Neurosci. 29, 6479-6489.

Giffin, F., and Mitchell, D. E. (1978). The rate of recovery of vision after early monocular deprivation in kittens. J. Physiol. 274, 511-537.

Hall, B. J., Ripley, B., and Ghosh, A. (2007). NR2B signaling regulates the development of synaptic AMPA receptor current. J. Neurosci. 27, 13446-13456.

Harauzov, A., Spolidoro, M., DiCristo, G., De Pasquale, R., Cancedda, L., Pizzorusso, T., Viegi, A., Berardi, N., and Maffei, L. (2010). Reducing intracortical inhibition in the adult visual cortex promotes ocular dominance plasticity. J. Neurosci. 30, 361-371.

Heinen, K., Bosman, L. W., Spijker, S., van Pelt, J., Smit, A. B., Voorn, P., Baker, R. E., and Brussaard, A. B. (2004). GABAA receptor maturation in relation to eye opening in the rat visual cortex. Neuroscience 124, 161-171.

Hensch, T. K. (2005). Critical period plasticity in local cortical circuits. Nat. Rev. Neurosci. 6, 877-888.
Hensch, T. K., and Fagiolini, M. (2005). Excitatory-inhibitorybalance and critical period plasticity in developing visual cortex. Prog. Brain Res. 147, 115-124.

Hensch, T. K., Fagiolini, M., Mataga, N., Stryker, M. P., Baekkeskov, S., and Kash, S. F. (1998). Local GABA circuit control of experience-dependent plasticity in developing visual cortex. Science 282, 1504-1508.

Herrmann, K. (1996). Differential distribution of AMPA receptors and glutamate during pre- and postnatal development in the visual cortex of ferrets. J. Comp. Neurol. 375, 1-17.

Hess, R. F., and Pointer, J. S. (1985). Differences in the neural basis of human amblyopia: the distribution of the anomaly across the visual field. Vision Res. 25, 1577-1594.

Heynen, A. J., Yoon, B. J., Liu, C. H., Chung, H. J., Huganir, R. L., and Bear, M. F. (2003). Molecular mechanism for loss of visual cortical responsiveness following brief monocular deprivation. Nat. Neurosci. 6, 854-862.

Hollingsworth,E.B.,McNeal,E.T., Burton, J. L., Williams, R. J., Daly, J. W., and Creveling, C. R. (1985). Biochemical characterization of a filtered synaptoneurosome preparation from guinea pig cerebral cortex: cyclic adenosine 3':5'-monophosphate-generating systems, receptors, and enzymes. J. Neurosci. 5, 2240-2253.

Hubel, D. H., and Wiesel, T. N. (1970). The period of susceptibility to the physiological effects of unilateral eye closure in kittens. J. Physiol. 206, 419-436.

Huttenlocher, P. R., de Courten, C., Garey, L. J., and Van der Loos, H. (1982). Synaptogenesis in human visual cortex--evidence for synapse elimination during normal development. Neurosci. Lett. 33, 247-252.

Iwai, Y., Fagiolini, M., Obata, K., and Hensch, T. K. (2003). Rapid critical period induction by tonic inhibition in visual cortex. J. Neurosci. 23 , 6695-6702.

Jonas, P., Racca, C., Sakmann, B. Seeburg, P. H., and Monyer, H. (1994) Differences in Ca2+ permeability of AMPA-type glutamate receptor channels in neocortical neurons caused by differential GluR-B subunit expression. Neuron 12, 1281-1289.

Kameyama, K., Sohya, K., Ebina, T., Fukuda, A., Yanagawa, Y., and Tsumoto, T. (2010). Difference in binocularity and ocular dominance plasticity between GABAergic and excitatory cortical neurons. J. Neurosci. 30, 1551-1559.

Kanold, P. O., Kim, Y. A., GrandPre, T., and Shatz, C. J. (2009). Co-regulation of ocular dominance plasticity and NMDA receptor subunit expression in glutamic acid decarboxylase-65 knock-out mice. J. Physiol. 587, 2857-2867.

Kiorpes, L., Kiper, D. C., O'Keefe, L. P., Cavanaugh, J. R., and Movshon, J. A. (1998). Neuronal correlates of amblyopia in the visual cortex of macaque monkeys with experimental strabismus and anisometropia. $J$. Neurosci. 18, 6411-6424.

Kirkwood, A., and Bear, M. F. (1994). Hebbian synapses in visual cortex. J. Neurosci. 14, 1634-1645.

Klausberger, T., Magill, P. J., Marton, L. F., Roberts, J. D., Cobden, P. M., Buzsaki, G., and Somogyi, P. (2003). Brainstate- and cell-type-specific firing of hippocampal interneurons in vivo. Nature 421, 844-848.

Kleinschmidt, A., Bear, M. F., and Singer, W. (1987). Blockade of "NMDA" receptors disrupts experience-dependent plasticity of kitten striate cortex. Science 238, 355-358.

Kleppe, I. C., and Robinson, H. P. (1999). Determining the activation time course of synaptic AMPA receptors from openings of colocalized NMDA receptors. Biophys. J. 77, 1418-1427.

Kutsuwada, T., Kashiwabuchi, N., Mori, H., Sakimura, K., Kushiya, E., Araki, K., Meguro, H., Masaki, H., Kumanishi, T., Arakawa, M., and Mishina, M. (1992). Molecular diversity of the NMDA receptor channel. Nature 358, 36-41.

Laurie, D. J., Wisden, W., and Seeburg, P. H. (1992). The distribution of thirteen GABAA receptor subunit mRNAs in the rat brain. III. Embryonic and postnatal development. J. Neurosci. 12, 4151-4172.

Le Roux, N., Amar, M., Baux, G., and Fossier, P. (2006). Homeostatic control of the excitation-inhibition balance in cortical layer 5 pyramidal neurons. Eur. J. Neurosci. 24, 3507-3518.

Li, X., Dumoulin, S. O., Mansouri, B., and Hess, R. F. (2007). Cortical deficits in human amblyopia: their regional distribution and their relationship to the contrast detection deficit. Invest. Ophthalmol. Vis. Sci. 48, 1575-1591.

Maffei, A., Lambo, M. E., and Turrigiano, G. G. (2010).Critical period for inhibitory plasticity in rodent binocular V1. J. Neurosci. 30, 3304-3309.

Maffei, A., Nataraj, K., Nelson, S. B., and Turrigiano, G. G. (2006). Potentiation of cortical inhibition by visual deprivation. Nature $443,81-84$.

Maffei, A., and Turrigiano, G. (2008a). The age of plasticity: developmental regulation of synaptic plasticity in neocortical microcircuits. Prog. Brain Res. 169, 211-223.

Maffei, A., and Turrigiano, G. G. (2008b). Multiple modes of network homeostasis in visual cortical layer $2 / 3$. J. Neurosci. 28, 4377-4384.

Majdan, M., and Shatz, C. J. (2006). Effects of visual experience on 
activity-dependent gene regulation in cortex. Nat. Neurosci. 9, 650-659.

Malenka, R. C., and Bear, M. F. (2004). LTP and LTD: an embarrassment of riches. Neuron 44, 5-21.

Marder E., and Goaillard J.M. (2006). Variability, compensation and homeostasis in neuron and network function. Nat. Rev. Neurosci. 7 , 563-574.

Marino, J., Schummers, J., Lyon, D. C., Schwabe, L., Beck, O., Wiesing, P., Obermayer, K., and Sur, M. (2005). Invariant computations in local cortical networks with balanced excitation and inhibition. Nat. Neurosci. 8, 194-201.

Maya Vetencourt, J. F., Sale, A., Viegi, A., Baroncelli, L., De Pasquale, R., O'Leary, O. F., Castren, E., and Maffei, L. (2008). The antidepressant fluoxetine restores plasticity in the adult visual cortex. Science 320, 385-388.

Miles, R., Toth, K., Gulyas, A. I., Hajos, N., and Freund, T. F. (1996). Differences between somatic and dendritic inhibition in the hippocampus. Neuron 16, 815-823.

Mitchell, D.E. (1988). The extent of visual recovery from early monocular or binocular visual deprivation in kittens. J. Physiol. 395, 639-660.

Mitchell,D.E.(1989).Normal and abnormal visual development in kittens: insights into the mechanisms that underlievisual perceptual development in humans. Can. J. Psychol. 43, 141-164.

Mohler, H. (1992). GABAergic synaptic transmission. Regulation by drugs. Arzneimittelforschung 42, 211-214.

Monyer, H., Burnashev, N., Laurie, D. J., Sakmann, B., and Seeburg, P. H. (1994). Developmental and regional expression in the rat brain and functional properties of four NMDA receptors. Neuron 12, 529-540.

Monyer, H., Sprengel, R., Schoepfer, R., Herb, A., Higuchi, M., Lomeli, H., Burnashev, N., Sakmann, B., and Seeburg, P. H. (1992). Heteromeric NMDA receptors: molecular and functional distinction of subtypes. Science 256, 1217-1221.

Movshon, J. A. (1976). Reversal of the physiological effects of monocular deprivation in the kitten's visual cortex. J. Physiol. 261, 125-174.

Mrsic-Flogel, T. D., Hofer, S. B., Ohki, K., Reid, R. C., Bonhoeffer, T., and Hubener, M. (2007). Homeostatic regulation of eye-specific responses in visual cortex during ocular dominance plasticity. Neuron 54, 961-972.

Murphy, K. M., Beston, B. R., Boley, P. M., and Jones, D. G. (2005). Development of human visual cortex: a balance between excitatory and inhibitory plasticity mechanisms. Dev. Psychobiol. 46, 209-221.
Murphy, K. M., Duffy, K. R., and Jones, D. G. (2004). Experience-dependent changes in NMDAR1 expression in the visual cortex of an animal model for amblyopia. Vis. Neurosci. 21, 653-670.

Murphy, K. M., and Mitchell, D. E. (1986). Bilateral amblyopia after a short period of reverse occlusion in kittens. Nature 323, 536-538.

Murphy, K. M., and Mitchell, D. E. (1987). Reduced visual acuity in both eyes of monocularly deprived kittens following a short or long period of reverse occlusion. J. Neurosci. 7, 1526-1536.

Murphy, K. M., and Mitchell, D. E. (1991). Vernier acuity of normal and visually deprived cats. Vision Res. 31, 253-266.

Nusser, Z., Sieghart, W., Benke, D., Fritschy, J. M., and Somogyi, P. (1996). Differential synaptic localization of two major gamma-aminobutyric acid type A receptor alpha subunits on hippocampal pyramidal cells. Proc. Natl. Acad. Sci. U.S.A. 93, 11939-11944.

O'Kusky, J., and Colonnier, M. (1982). Postnatal changes in the number of neurons and synapses in the visual cortex (area 17) of the macaque monkey: a stereological analysis in normal and monocularly deprived animals. J. Comp. Neurol. 210, 291-306.

Olson, C. R., and Freeman, R. D. (1980). Profile of the sensitive period for monocular deprivation in kittens. Exp. Brain Res. 39, 17-21.

Philpot, B. D., Espinosa, J. S., and Bear, M. F. (2003). Evidence for altered NMDA receptor function as a basis for metaplasticity in visual cortex. J. Neurosci. 23, 5583-5588.

Philpot, B. D., Sekhar, A. K., Shouval, H.Z., and Bear, M. F. (2001). Visual experience and deprivation bidirectionally modify the composition and function of NMDA receptors in visual cortex. Neuron 29, 157-169.

Quinlan, E. M., Olstein, D. H., and Bear, M. F. (1999a). Bidirectional, experience-dependent regulation of N-methyl-D-aspartate receptor subunit composition in the rat visual cortex during postnatal development. Proc. Natl. Acad. Sci. U.S.A. 96, 12876-12880.

Quinlan, E. M., Philpot, B. D., Huganir, R. L., and Bear, M. F. (1999b). Rapid, experience-dependent expression of synaptic NMDA receptors in visual cortex in vivo. Nat. Neurosci. 2, 352-357.

Ramoa, A. S., Mower, A. F., Liao, D., and Jafri, S. I. (2001). Suppression of cortical NMDA receptor function prevents development of orientation selectivity in the primary visual cortex. $J$. Neurosci. 21, 4299-4309.

Rittenhouse, C. D., Shouval, H. Z., Paradiso, M.A., and Bear, M.F. (1999).
Monocular deprivation induces homosynaptic long-term depression in visual cortex. Nature 397, 347-350.

Roberts, E. B., Meredith, M.A., and Ramoa, A. S. (1998). Suppression of NMDA receptor function using antisense DNA block ocular dominance plasticity while preserving visual responses. $J$. Neurophysiol. 80, 1021-1032.

Roberts, E. B., and Ramoa, A. S. (1999). Enhanced NR2A subunit expression and decreased NMDA receptor decay time at the onset of ocular dominance plasticity in the ferret. J. Neurophysiol. 81, 2587-2591.

Sieghart, W. (1992). Pharmacology of benzodiazepine receptors: an update. Clin. Neuropharmacol. 15 (Suppl. 1 Pt A), 523A-524A.

Sieghart, W., Fuchs, K., Tretter, V., Ebert, V., Jechlinger,M.,Hoger,H., and Adamiker, D. (1999). Structure and subunit composition of GABA(A) receptors. Neurochem. Int. 34, 379-385.

Smith, S. L., and Trachtenberg, J. T. (2007). Experience-dependent binocular competition in the visual cortex begins at eye opening. Nat. Neurosci. 10, 370-375.

Southwell, D. G., Froemke, R. C., AlvarezBuylla, A., Stryker, M. P., and Gandhi, S.P. (2010). Cortical plasticity induced by inhibitory neuron transplantation. Science 327, 1145-1148.

Stocca, G., and Vicini, S. (1998). Increased contribution of NR2A subunit to synaptic NMDA receptors in developing rat cortical neurons. J. Physiol. $507(\mathrm{Pt}$ 1), 13-24.

Strack, S., and Colbran, R. J. (1998). Autophosphorylation-dependent targeting of calcium/calmodulindependent protein kinase II by the NR2B subunit of the N-methyl-Daspartate receptor. J. Biol. Chem. 273, 20689-20692.

Tanaka, S., Tani, T., Ribot, J., O’Hashi, K., and Imamura, K. (2009). A postnatal critical period for orientation plasticity in the cat visual cortex. PLoS ONE 4:e5380. doi: 10.1371/journal. pone. 0005380 .

Taylor, A. L., Hickey, T. J., Prinz, A. A., and Marder, E. (2006). Structure and visualization of high- dimensional conductance spaces. J. Neurophysiol. 96, 891-905.

Timney, B. (1981). Development of binocular depth perception in kittens. Invest. Ophthalmol. Vis. Sci. 21, 493-496.

Tropea, D., Kreiman, G., Lyckman, A., Mukherjee, S., Yu, H., Horng, S., and Sur, M. (2006). Gene expression changes and molecular pathways mediating activity-dependent plasticity in visual cortex. Nat. Neurosci. 9, 660-668.

Turrigiano, G. G., and Nelson, S. B. (2004). Homeostatic plasticity in the develop- ing nervous system. Nat. Rev. Neurosci. 5, 97-107.

Tusa, R. J., Palmer, L. A., and Rosenquist, A.C. (1978). The retinotopic organization of area 17 (striate cortex) in the cat. J. Comp. Neurol. 177, 213-235.

Van den Bergh, G., Clerens, S., Firestein, B. L., Burnat, K., and Arckens, L. (2006). Development and plasticity-related changes in protein expression patterns in cat visual cortex: a fluorescent two-dimensional difference gel electrophoresis approach. Proteomics 6, 3821-3832.

Ward, G. J. (1994). "The RADIANCE lighting simulation and rendering system," in Proceedings of the 21st Annual Conference on Computer Graphics and Interactive Techniques, SIGGRAPH 94, ed. A. Glassner (New York: ACM Press), 459-472.

Whiting, P. J., Bonnert, T. P., McKernan, R. M., Farrar, S., Le Bourdelles, B., Heavens, R. P., Smith, D. W., Hewson, L., Rigby, M. R., Sirinathsinghji, D. J., Thompson, S. A., and Wafford, K. A. (1999). Molecular and functional diversity of the expanding GABA-A receptor gene family. Ann. N. Y. Acad. Sci. 868, 645-653.

Wierenga, C. J., Ibata, K., and Turrigiano, G. G. (2005). Postsynaptic expression of homeostatic plasticity at neocortical synapses. J. Neurosci. 25, 2895-2905.

Wiesel, T. N., and Hubel, D. H. (1965). Comparison of the effects of unilateral and bilateral eye closure on cortical unit responses in kittens. J. Neurophysiol. 28, 1029-1040.

Yazaki-Sugiyama, Y., Kang, S., Cateau, H., Fukai, T., and Hensch, T. K. (2009). Bidirectional plasticity in fast-spiking GABA circuits by visual experience. Nature 462, 218-221.

Conflict of Interest Statement: The authors declare that the research was conducted in the absence of any commercial or financial relationships that could be construed as a potential conflict of interest.

Received: 25 March 2010; paper pending published: 23 June 2010; accepted: 06 August 2010; published online: 28 September 2010.

Citation: Beston BR, Jones DG and Murphy KM (2010) Experience-dependent changes in excitatory and inhibitory receptor subunit expression in visual cortex. Front. Syn. Neurosci. 2:138 doi:10.3389/ fnsyn. 2010.00138

Copyright (๑) 2010 Beston, Jones and Murphy. This is an open-access article subject to an exclusive license agreement between the authors and the Frontiers Research Foundation, which permits unrestricted use, distribution, and reproduction in any medium, provided the original authors and source are credited. 